\title{
Sphingolipids and plant defense/disease: the "death" connection and beyond
}

\author{
Robert Berkey ${ }^{1,2}$, Dipti Bendigeri ${ }^{1,2}$ and Shunyuan Xiao ${ }^{1,2 *}$ \\ 1 Institute for Bioscience and Biotechnology Research, University of Maryland, Rockville, MD, USA \\ ${ }^{2}$ Department of Plant Sciences and Landscape Architecture, University of Maryland, College Park, MD, USA
}

\section{Edited by:}

Xuemin Wang, University of Missouri-St Louis and Donald Danforth Plant Science Center, USA

Reviewed by:

Kian Hématy, Institut National de la Recherche Agronomique, France

Beatrice Satiat-Jeunemaitre, Centre National de la Recherche Scientifique, France

Carl Ng, University College Dublin, Ireland

Marina Gavilanes-Ruiz, Universidad

Nacional Autonoma de Mexico,

Mexico

Dominique Roby, Centre National de la Recherche Scientifique, France

\section{${ }^{*}$ Correspondence:}

Shunyuan Xiao, Institute for

Bioscience and Biotechnology

Research, University of Maryland,

Rockville, MD 20850, USA.

e-mail:xiao@umd.edu
Sphingolipids comprise a major class of structural materials and lipid signaling molecules in all eukaryotic cells. Over the past two decades, there has been a phenomenal growth in the study of sphingolipids (i.e., sphingobiology) at an average rate of $\sim 1000$ research articles per year. Sphingolipid studies in plants, though accounting for only a small fraction $(\sim 6 \%)$ of the total number of publications, have also enjoyed proportionally rapid growth in the past decade. Concomitant with the growth of sphingobiology, there has also been tremendous progress in our understanding of the molecular mechanisms of plant innate immunity. In this review, we (i) cross examine and analyze the major findings that establish and strengthen the intimate connections between sphingolipid metabolism and plant programmed cell death (PCD) associated with plant defense or disease; (ii) highlight and compare key bioactive sphingolipids involved in the regulation of plant PCD and possibly defense; (iii) discuss the potential role of sphingolipids in polarized membrane/protein trafficking and formation of lipid rafts as subdomains of cell membranes in relation to plant defense; and (iv) where possible, attempt to identify potential parallels for immunity-related mechanisms involving sphingolipids across kingdoms.

Keywords: sphingolipid, programmed cell death, hypersensitive response, defense, polarized trafficking, lipid raft, pathogen, Arabidopsis

\section{INTRODUCTION}

Plants are sessile and lack a somatically adaptive immune system. Yet, plants have evolved a complex innate immune system that can effectively protect plants against various pathogens. It is believed that individual plant cells have the capacity for pathogen detection and onsite defense activation. Conceivably, these complex (sub)cellular processes must rely on an elaborate membrane system. Indeed, sphingolipids as bioactive molecules have been extensively involved in plant programmed cell death (PCD) associated with defense, and more recently as signaling and/or structural materials implicated in regulation of membrane trafficking and/or formation of membrane subdomains during defense response. Here we provide a focused review on this process. In order for readers to better understand the potential mechanistic connections between plant defense/disease and sphingolipid metabolism, we start off with a brief introduction on plant innate immunity and its connection to plant PCD. Also, for the convenience of readers, we list the most relevant abbreviations used in this review in Table 1.

It is known that plants have evolved two major evolutionarily interconnected branches of induced immunity (Chisholm et al., 2006; Thomma et al., 2011). The first is activated upon recognition of non-self molecules conserved in pathogens called pathogenassociated molecular patterns (PAMPs) by plasma membranelocalized transmembrane immune receptors (Chisholm et al., 2006). PAMP-triggered immunity (PTI) contributes to general resistance of plants to all potential pathogens. Adapted pathogens secrete effector proteins into host cells to interfere with PTI (Chisholm et al., 2006). Plants have thus evolved the second branch of immune response that is activated upon recognition of specific pathogen effectors mostly by intracellular immune receptors [which are historically referred to as resistance (R) proteins] belonging to the conserved nucleotide-site binding and leucine-rich repeat (NB-LRR) family (Jones and Dangl, 2006).

Effector-triggered immunity (ETI) protects plants from hostadapted biotrophic and hemi-biotrophic pathogens whose colonization on plants requires living host cells (Glazebrook, 2005; Jones and Dangl, 2006). ETI is often although not always associated with hypersensitive response (HR), which is rapid PCD at the site of infection (Heath, 2000). There are different forms of plant PCD and their definitions are still in debate (Reape et al., 2008; van Doorn et al., 2011). According to a most recent view by van Doorn (2011), plant PCD can be divided into two major classes: (i) autolytic PCD and (ii) non-autolytic PCD. Autolytic PCD occurs mostly during normal plant development and features the formation of large lytic vacuoles, activation of vacuolar processing enzymes (VPEs), and rapid clearance of the cytoplasm, whereas non-autolytic PCD occurs mainly during pathogen attack and lacks rapid cytoplasm clearance. According to this classification, HR cell death belongs to non-autolytic PCD, even though it may exhibit disruption of the tonoplast and activation of VPEs as 
Table 1 | A list of abbreviations used in this review.

\begin{tabular}{ll}
\hline Abbreviation & Full name (explanation) \\
\hline AAL & Alternaria alternata f. sp. Iycopersici toxin \\
ACD5 & Accelerated cell death 5 \\
ACD11 & Accelerated cell death 11 \\
Cer-1-P & Ceramide-1-phosphate \\
CerS & Ceramide synthase \\
d18:0 & Dihydrosphingosine/sphinganine \\
DRM & Detergent-resistant membrane \\
EDS1 & Enhanced disease susceptibility 1 \\
ERH1 & Enhancing RPW8 HR-like cell death 1 \\
ETI & Effector-triggered immunity \\
FAH1/2 & Fatty acid 2-hydroxylase 1/2 \\
FB1 & Fumonisin B1 toxin \\
GICCer & Glucosylceramide \\
GIPC & Glycosyl inositol-phosphorylceramide \\
IPC & Inositol-phosphorylceramide \\
IPCS & Inositol-phosphorylceramide synthase \\
LCB1 & Gene encoding subunit 1 of SPT \\
LCB2 & Gene encoding subunit 2 of SPT \\
LCB & Long-chain base \\
LCB-P & Long-chain base phosphate \\
LOH1/2/3 & LAG One Homolog 1/2/3 \\
PAD4 & Phytoalexin-Deficient 4 \\
PAMP & Pathogen-associated molecular pattern \\
Phyto-S1P & Phytosphingosine-1-phosphate \\
PTI & PAMP-triggered immunity \\
SBH1/2 & Sphingoid base hydroxylase 1/2 \\
ShpK & Sphingosine kinase \\
S1P & Sphingosine-1-phosphate \\
SPI-PCD & Sphingolipid-perturbation induced PCD \\
SPT & Serine palmitoyltransferase \\
t18:0 & Phytosphingosine/4-hydroxysphinganine \\
VLCFA & VPE \\
\hline
\end{tabular}

seen in autolytic cell death (van Doorn, 2011). The salicylic acid (SA)-signaling pathway is required for HR development, because depletion of SA or impairing SA-signaling by mutations in immunity proteins like EDS1 and PAD4 often abolish resistance as well as HR (Wiermer et al., 2005). The precise role of HR in ETI remains unclear; at least the quick suicide of infected cells may physically constrain invading biotrophic pathogens including viruses, fungi, and oomycetes (Heath, 2000; Mur et al., 2008; Coll et al., 2011). However, for necrotrophic fungal pathogens that do not require living plant cells to establish parasitism, plant cell death including HR cannot stop their infection; rather, HR could facilitate infection and spread of disease (Govrin and Levine, 2000; Mayer et al., 2001; Glazebrook, 2005). Furthermore, one common virulence mechanism for necrotrophic pathogens is to secrete toxins into the host and induce host cell death (Friesen et al., 2008; Lawrence et al., 2008; Sweat et al., 2008; Lorang et al., 2010; Oliver and Solomon, 2010) and plants that are less potent in activation of HR show enhanced tolerance to necrotrophic pathogens (El Oirdi and Bouarab, 2007).
In the past two decades, while significant progress has been made toward our understanding of the molecular mechanisms concerning PTI and ETI, little is known regarding plant resistance to necrotrophic pathogens (Oliver and Solomon, 2010). However, extensive studies have been conducted on how mycotoxins produced by necrotrophic fungal pathogens induce plant (and animal) PCD and disease. The use of such PCD-inducing mycotoxins as tools to study the cellular functions of sphingolipids has significantly contributed to the rapid growth of sphingobiology across kingdoms. To date, although studies crosslinking sphingolipids and plant immunity are still sporadic, there is increasing evidence to suggest important roles for sphingolipids in modulation of plant PCD (non-autolytic cell death) associated with defense and disease. This review will examine how sphingolipids may be mechanistically connected to the plant defense from the following aspects: (i) implications of sphingolipid-perturbation-induced PCD (SPI-PCD) in plant disease and defense, (ii) potential bioactive sphingolipids as signaling molecules in plant PCD and defense, and (iii) sphingolipids in lipid raft formation and polarized membrane/protein trafficking associated with plant defense.

\section{SPHINGOLIPID METABOLISM IN PLANTS}

In order to examine and understand the complex plausible connections between sphingolipid metabolism and plant disease or defense, it is necessary to give a brief introduction to sphingolipids and their metabolism in plants. For a thorough understanding of sphingolipid metabolism, the reader is referred to many excellent recent reviews on this subject (Dunn et al., 2004; Breslow and Weissman, 2010; Pata et al., 2010; Hannun and Obeid, 2011; Merrill, 2011).

All complex sphingolipids are composed of a sphingoid longchain base (LCB) linked via the amide bond to an $N$-acylated fatty acid (FA) to yield ceramide (the basic unit of all sphingolipids) and a polar head group (Figure 1; Gault et al., 2010; Pata et al., 2010; Merrill, 2011). In some literature, the term "sphingolipids" also covers sphingoid LCB derivatives and for convenience we will use this broader definition of sphingolipid in this review. As shown in Figure 1, the extremely high structural diversity of sphingolipids is attributed to (a) the length of the sphingoid LCB (the most common chain being 18 carbon atoms) and the $N$-acylated FA chain (often ranging from 14 to 36 carbon atoms; Breslow and Weissman, 2010; Merrill, 2011), (b) the degree of hydroxylation, and number and position of double bond in the LCB, (c) the saturation and hydroxylation status of the FA, and (d) the substituent as the head group at position 1 of the basic ceramides (which contains a simple hydroxyl group; Breslow and Weissman, 2010; Tafesse and Holthuis, 2010; Merrill, 2011). Thus, the resulting eukaryotic sphingolipidome is very complex, comprising up to thousands of sphingoid bases and their derivatives, which has perplexed “sphingobiologists" for decades (Merrill et al., 2007, 2009). For example, one recent sphingolipid profiling assay alone identified over 200 sphingolipids in Arabidopsis leaves (Markham et al., 2006; Markham and Jaworski, 2007). It is the structural diversity of sphingolipids that is believed to enable their diverse cellular functions including those related to immunity in plants and other eukaryotic organisms. There is a convenient short-hand nomenclature to describe sphingolipids with structural features (Chen 


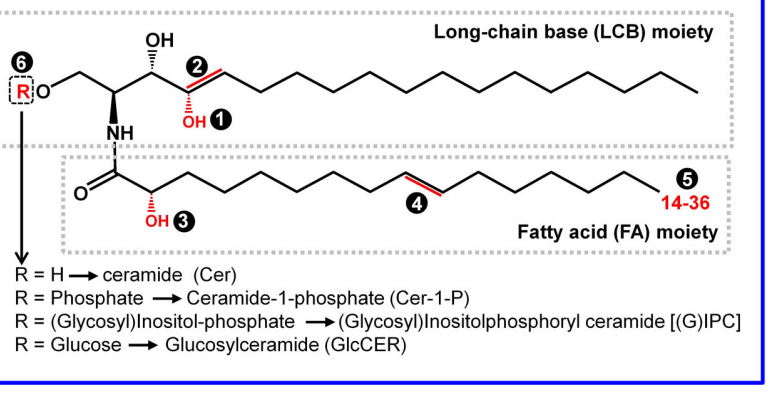

FIGURE 1 |The basic structure, building blocks, and sources for structural diversity of sphingolipids. All the structural variables are highlighted in red and indicated by a number in a shaded circle. Ceramide (Cer) is the fundamental unit of all complex sphingolipids. The Cer core consists of two structural moieties: the sphingoid long-chain base (LCB) and the fatty acid (FA) chain linked via an amide bond. The typical LCB has a chain length of 18 carbons, which may be hydroxylated at 4-position $\mathbf{1}$, or have a double bond at the 4 or 8 carbon 2. The FA chain may be hydroxylated at the $\alpha$-position 3 , and/or have a double bond at $\omega 9$-position 4 . The FA chain length may vary from 14 to 36 (if $>20$, it is referred to as very long-chain FA, i.e., VLCFA) 5 . The structurally diverse ceramides can be converted to more complex sphingolipids via substitution of the head group designated $\mathrm{R}$ at the 1-position of the LCB 6 . Additional sugar residues may be further added to IPCs and GICCERs, resulting in more complex sphingolipids.

et al., 2010; Merrill, 2011). For example, d18:1/C16:0 refers to a ceramide consisting of dihydrosphingosine with an $\underline{18}$ carbon chain plus $\underline{1}$ double bond (d18:0), and an amide-linked $\underline{\mathrm{C} 16}$ FA chain with $\underline{0}$ double bond (C16:0).

Despite the structural diversity, sphingolipid metabolism is generally conserved in animals, yeast, and plants (Hannun and Obeid, 2008; Merrill, 2011). Complex sphingolipids can be formed via two major pathways: the de novo biosynthesis pathway, starting with the condensation of a serine with an acyl-CoA; and the salvage pathway, where ceramides and LCBs as catabolites of more complex sphingolipids re-enter the synthetic pathway (Kitatani et al., 2008; Pata et al., 2010; Merrill, 2011). The major steps of the biosynthesis of sphingolipids and their modification and degradation pathways have been elucidated in yeast and other eukaryotic organisms (see excellent reviews by Breslow and Weissman, 2010; Hannun and Obeid, 2011; Merrill, 2011). To help the reader better understand our focused review, we highlight here the major known steps of sphingolipid metabolism in plants (Figure 2).

As depicted in Figure 2, sphingolipid biosynthesis begins in the endoplasmic reticulum (ER) with the condensation of serine and fatty acyl-CoA. This reaction is catalyzed by the enzyme serine palmitoyltransferase (SPT) and yields the first of a series of LCBs (Tafesse and Holthuis, 2010; Merrill, 2011). The resulting LCBs become acylated and are further modified to form ceramides - the backbone of more complex sphingolipids (Tafesse and Holthuis, 2010). Ceramides are then transported to the Golgi complex, where they acquire a species-specific array of polar head groups to form the complex sphingolipids such as sphingomyelin (SM; in animals), (glycosyl) inositol-phosphorylceramides [(G)IPCs; in plants and fungi], and various glucosylceramides (GlcCERs) found primarily on the cell surface (Tafesse and Holthuis, 2010). Thus, the four major classes of plant sphingolipids are free LCBs, ceramides, GIPCs, and GlcCERs. Although GIPCs and GlcCERs are much more abundant $(>10 \times)$ than LCBs and ceramides in plant cells (Markham et al., 2006; Markham and Jaworski, 2007), their biological functions beyond structural roles in membrane formation are poorly characterized. By contrast, like in yeast and animals, less abundant LCBs and ceramides and their derivatives formed via phosphorylation and hydroxylation, are known to be implicated in regulation of multiple important cellular functions in plants, such as stomata closure mediated by ABA signaling (Coursol et al., 2003; Michaelson et al., 2009; Quist et al., 2009) and plant PCD (see later text). Thus, their relative levels are thought to be tightly regulated. Recent studies in yeast suggest that two yeast homologs of human orosomucoid (Orm) proteins Orm1 and Orm 2 function as a rheostat to regulate sphingolipid synthesis and these two proteins are regulated via phosphorylation by the protein kinase Ypk1 (Breslow et al., 2010; Han et al., 2010; Roelants et al., 2011). Mutations in human Orm-like protein 3 (ORMDL3) gene are associated with susceptibility to multiple pathological disorders, indicating the importance of a tight regulation of sphingolipid metabolism (Breslow et al., 2010; Jin et al., 2011). A BLAST search also identified two likely Orm homologs, At1G01230 and At5G42000 in the Arabidopsis genome. It is possible that these Orm-like genes serve similar regulatory function in plants.

\section{THE "DEATH" CONNECTIONS BETWEEN SPHINGOLIPID METABOLISM AND PLANT DEFENSE/DISEASE "DEATH" CONNECTION I: FUNGAL TOXINS AND PLANT DISEASES}

Plants and their pathogens engage in a long lasting warfare to survive and thrive. The strategies for infection and defense depends on the modes of parasitism: necrotrophs kill and feed on hosts whereas biotrophs co-survive with their hosts and thus suppress cell death (HR) to enable infection. Thus control of the host cell fate at the site of infection is a key battle between plants and their pathogens.

Retrospectively, the identification of two major groups of toxins AAL (named from initials of the producing pathogen; see below) and fumonisin B1 (FB1) from plant necrotrophic pathogens coincided with and facilitated early research on sphingolipid metabolism and its cellular functions in yeast, plants, and animals. Although numerous studies have been conducted with AAL and FB1 as inhibitor of the acyl-CoA-dependent ceramide synthases (CerSs), there are only a few investigations focusing on whether $\mathrm{AAL}$ and FB1 contribute to virulence of the necrotrophic fungal pathogens. Here, we examine the "death" connection between these two toxins and fungal virulence.

\section{Fungal toxin $A A L$ as a virulence factor induced $P C D$}

In search for the fungal factor of Alternaria alternata f. sp. lycopersici, a necrotrophic pathogen causing stem canker disease on certain tomato cultivars, Gilchrist and colleagues isolated (Gilchrist and Grogan, 1976) and purified (Clouse et al., 1985) the fungal toxin AAL that induced the stem canker disease symptom. In these studies, they also found that resistance of tomato to the toxin is controlled by a single dominant gene named Asc (Gilchrist and Grogan, 1976). Genetically, Asc is a typical $R$ gene that counteracts 


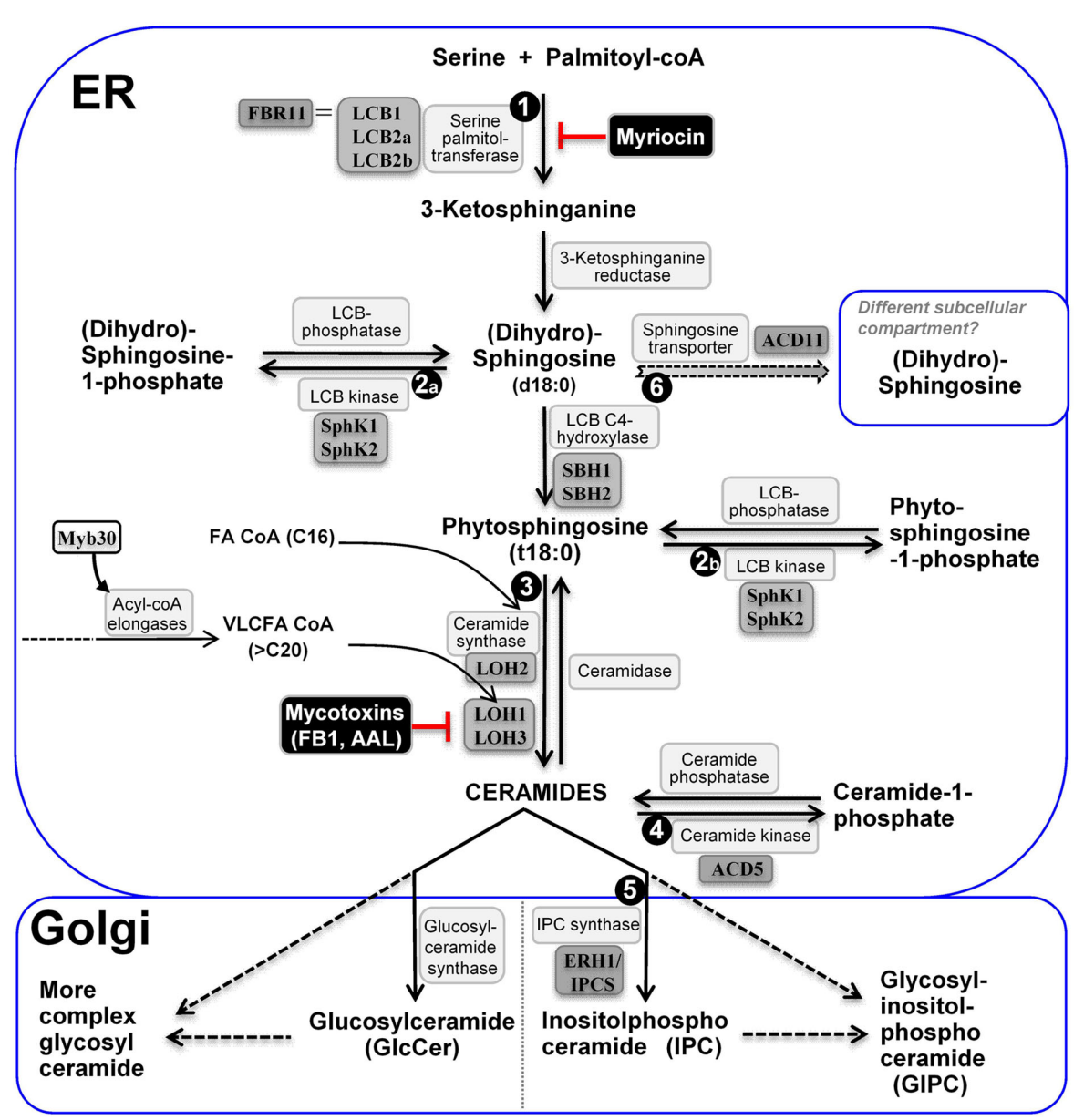

FIGURE 2 |The major steps of sphingolipid metabolism in plants. De novo ceramide synthesis occurs in the ER and synthesis of more complex sphingolipids occurs in the Golgi apparatus. The metabolic steps genetically characterized to be critical for plant PCD regulation are enumerated $\mathbf{0}$ to 6 Name of enzymes are in white boxes, and genetically characterized ones in gray boxes; Uncharacterized steps are linked with dashed lines. the activity of a virulence factor, in this case the AAL toxin. Later, Akamatsu et al. (1997) made 3 AAL-toxin-deficient mutants of A. alternata f. sp. lycopersici and found that these fungal mutants could not cause symptoms on susceptible tomato, indicating that the toxin is required for pathogenicity of the fungus (Akamatsu et al., 1997). AAL was later found to be a potent inducer of plant PCD (Mirocha et al., 1992; Witsenboer et al., 1992; Gilchrist et al., 1995a; Wang et al., 1996b), apoptosis and other maladies in a wide range of animal cells (Shier et al., 1991; Abbas et al., 1995b; Gilchrist et al., 1995b; Wang et al., 1996a), with typical features of PCD such as DNA fragmentation, laddering, and caspase activation (in animal cases). The structure of AAL was resolved and was found to be structurally analogous to sphingosine (Shier et al., 1995), implicating sphingolipid metabolism in plant PCD and animal apoptosis (Mirocha et al., 1992; Abbas et al., 1994, 1995a; Gilchrist et al., 1995b).

Asc was cloned in 2000 by Brandwagt and colleagues and found to share homology to the yeast longevity assurance gene LAG1 (D'Mello et al., 1994; Brandwagt et al., 2000). AAL-sensitive tomato (asc/asc) genotypes bear loss-of-function mutations in the Asc gene (Brandwagt et al., 2000; Spassieva et al., 2002). Overexpression of Asc was found to confer insensitivity to another sphingosine analog, mycotoxin FB1 and resistance to plant infection by A. alternata f. sp. lycopersici (Brandwagt et al., 2002).

Yeast LAG1 and its close homolog LAC1, and their mammalian homologs encode acyl-CoA-dependent CerSs (Schorling et al., 2001; Guillas et al., 2003; Riebeling et al., 2003). Consistent with AAL being a sphingosine analog, AAL has been shown to be a potent inhibitor of CerSs in yeast and animals (Abbas et al., 1994; Gilchrist et al., 1995b; Riebeling et al., 2003; Figure 2). Asc is thus predicted to encode a plant acyl-CoAdependent CerS, although biochemical evidence has not been provided. Based on the biochemical nature of AAL and its target enzyme CerS, there are two possible mechanisms underlying AALinduced PCD in plants (and animals): (i) accumulation of LCBs [dihydrosphingosine (sphinganine; d18:0) and phytosphingosine (4-hydroxysphinganine; t18:0); Wang et al., 1996b; Brandwagt et al., 2000] or (ii) ceramide deficiency. However, because blocking the first step of sphingolipid synthesis by myriocin, another fungal toxin, alleviates PCD induced by AAL, this suggests that a 
decrease in de novo ceramide synthesis is not, by itself, the cause for AAL-induced PCD (Spassieva et al., 2002). Thus it appears that it is the accumulation of LCBs due to inhibition of CerS activity by AAL that triggers PCD. Alternatively, the ratio of LCBs/ceramides may constitute a switch, triggering PCD (Spassieva et al., 2002). These findings stimulated studies of LCBs as signaling molecules involved in multiple cellular processes in yeast, plants and animals (see later text for more details).

\section{Fumonisin as a virulence factor induces PCD}

Fumonisins comprise another group of fungal toxins that are structural analogs of sphingosine and potent inhibitors of acylCoA-dependent CerSs (Merrill et al., 1993; Abbas et al., 1994; Gilchrist et al., 1995a; Figure 2). These toxins are produced by several species of Fusarium molds such as F. verticillioides and F. moniliforme capable of infecting many cereal crops such as maize, wheat, and barley (Sydenham et al., 1990; Thiel et al., 1991). Thus, food and feed contamination with fumonisins presents a serious safety concern to animals and humans (Sydenham et al., 1990; Marasas, 2001; Grenier and Oswald, 2011).

Fumonisin B1 is the most prevalent member of this toxin family and has been widely used as a probe to investigate the cellular functions of sphingolipid metabolism in yeast and animals (Abbas et al., 1994, 1995b; Wang et al., 1996a; Schmelz et al., 1998; Riebeling et al., 2003). In contrast, relatively little is known about the physiological effect of fumonisins from fungal pathogens in the natural environment on the development of plant diseases. Earlier studies with maize pathogens Fusarium spp. revealed positive correlations between production of FB1 and levels of virulence (Desjardins et al., 1995; Desjardins and Plattner, 2000; Williams et al., 2007). More recently, through molecular and genetic studies, Glenn et al. (2008) identified the fumonisin biosynthetic gene cluster in F. verticillioides infectious on maize seedlings. They generated mutant strains in which a polyketide synthase gene (FUM1) is disrupted and production of fumonisins is abrogated and found that these mutant strains were not pathogenic on maize seedlings, thus providing genetic evidence that fumonisin production by $F$. verticillioides is required for development of foliar disease symptoms on maize seedlings (Glenn et al., 2008). In addition, Sanchez-Rangel et al. (2011) found that $F$. verticillioides and pure FB1 toxin suppress the activities of two basic isoforms of maize $\beta$-1,3-glucanase (PR2-like proteins). Hence they suggested that $\beta$-1,3-glucanases are relevant physiological targets of FB1 and their suppression by FB1 might contribute to F. verticillioides virulence (Sanchez-Rangel et al., 2011).

Compared to AAL, FB1 has been more widely used as a tool to study the connection of PCD due to perturbation of sphingolipid metabolism and activation of plant defense. Of note, Stone et al. (2000) found that FB1-induced cell death in Arabidopsis is associated with generation of ROS, deposition of phenolic compounds and callose, accumulation of phytoalexin, and expression of pathogenesis-related $(P R)$ genes, which is mechanistically similar to HR in ETI. Furthermore, they showed that FB1-induced cell death in Arabidopsis protoplasts requires jasmonate-, ethylene-, and SA-dependent signaling pathways (Asai et al., 2000). These results provide strong evidence to support the notion that the execution of PCD induced by FB1 and HR share some basic cellular mechanisms.

Kuroyanagi et al. (2005) further showed that VPE, which is essential for HR development, is also required for FB1-induced cell death in Arabidopsis (Kuroyanagi et al., 2005). FB1-induced cell death was accompanied with disruption of vacuolar membrane followed by lesion formation. The features of FB1-induced cell death were completely abolished in the Arabidopsis VPE-null mutant. Because VPE shows caspase-1-like activity in plants and is essential for HR cell death, this finding links FB1-induced to HR and apoptosis in animals (Kuroyanagi et al., 2005).

Furthermore, Li et al. (2008) showed that a (caspase-like) serine protease (Kunitz trypsin) inhibitor (KTI1) of Arabidopsis is induced late in response to bacterial and fungal elicitors and to exogenous SA (Li et al., 2008). RNAi silencing of the AtKTI1 gene resulted in enhanced leaf $\mathrm{PCD}$ induced by FB1 or HR induced by an avirulent bacterial pathogen Pseudomonas syringae pv tomato DC3000 carrying avrB. Overexpression of AtKTI1 on the other hand reduced FB1-induced PCD and the HR (Li et al., 2008), again suggesting that FB1-induced PCD is mechanistically connected with HR.

In summary, studies on the mode-of-action(s) for two fungal toxins AAL and FB1 have collectively revealed that induction of plant PCD due to inhibition of the acyl-CoA-dependent CerS is a virulence strategy of necrotrophic pathogens and suggested that there is an intimate connection between sphingolipid metabolism and plant PCD associated with plant disease caused by necrotrophs and possibly with plant defense against biotrophs.

\section{“DEATH” CONNECTION II: ARABIDOPSIS MUTANTS IDENTIFIED BY FORWARD GENETICS}

Since HR often occurs during ETI and shows similar molecular and physiological features with PCD induced by fungal toxins and other pathogen elicitors, one strategy to elucidate the genetic components that negatively regulate HR is to identify and characterize genetic mutations that result in HR-like cell death and constitutive expression of SA-dependent $P R$ genes. Many such so-called lesionmimic Arabidopsis mutants have been isolated and characterized in the past two decades. Collectively, these studies have revealed several regulatory mechanisms contributing to plant PCD associated with defense (reviewed by Lorrain et al., 2003; Moeder and Yoshioka, 2008). A few genes identified by this forward genetics approach are predicted to encode proteins involved in sphingolipid metabolism (Table 2), thus providing solid genetic evidence for the connection between sphingolipid metabolism and plant PCD associated with defense.

\section{FBR11 - a subunit of the serine palmitoyltransferase}

Given that FB1-induced PCD shares common features of HR, a facile genetic screen using FB1 as a PCD inducer identified two FB1-resistant in Arabidopsis mutants fbr1 and fbr2 (no cell death in the presence of $1 \mu \mathrm{M}$ FB1 on agar medium; Stone et al., 2000). Though no further report on the identity of the two mutations, a T-DNA insertion-mediated knockdown mutant named fbr11-1 was identified using a similar mutant screening scheme (Shi et al., 2007). FBR11(At4g36480) encodes a long-chain base 1 (LCB1) subunit of SPT (Shi et al., 2007). SPT catalyzes the first 
Table 2 | Characterized Arabidopsis genes implicated in sphingolipid-perturbation induced PCD related to defense.

\begin{tabular}{|c|c|c|c|c|c|}
\hline Gene symbol & Gene ID & Gene product & PCD-related phenotypes & $\begin{array}{l}\text { Possible mechanisms } \\
\text { involved }\end{array}$ & Reference \\
\hline LCB1 (FBR11) & At4g36480 & $\begin{array}{l}\text { Subunit of } \\
\text { serine palmi- } \\
\text { toyltransferase } \\
\text { (SPT) }\end{array}$ & $\begin{array}{l}\text { The fbr11-1 knockdown mutant is less } \\
\text { sensitive to FB1-induced }\end{array}$ & Low levels of LCBs & $\begin{array}{l}\text { Chen et al. (2006), Shi } \\
\text { et al. (2007) }\end{array}$ \\
\hline$\angle C B 2 a$ & At5g23670 & $\begin{array}{l}\text { Subunit } 2 \text { of } \\
\text { SPT }\end{array}$ & $\begin{array}{l}\text { The Icb2a knockout mutant is less } \\
\text { sensitive to FB1-induced PCD }\end{array}$ & Low levels of LCBs & $\begin{array}{l}\text { Saucedo-Garcia et al. } \\
\text { (2011b) }\end{array}$ \\
\hline $\mathrm{SBH} 1 / \mathrm{SBH} 2$ & $\begin{array}{l}\text { At1g14290/ } \\
\text { At1g69640 }\end{array}$ & $\begin{array}{l}\text { Sphingolipid- } \\
\text { C4- } \\
\text { hydroxylase }\end{array}$ & $\begin{array}{l}\text { The double mutant is dwarfed and with } \\
\text { PCD spots }\end{array}$ & $\begin{array}{l}\text { Higher levels of } \\
\text { C16-sphingolipids and lower } \\
\text { levels of VLCFA-sphingolipids, } \\
\text { and/or lack of trihydroxy LCBs }\end{array}$ & Chen et al. (2008) \\
\hline SphK1/SphK2 & $\begin{array}{l}\text { At4g21540/ } \\
\text { At2g46090 }\end{array}$ & $\begin{array}{l}\text { sphingosine } \\
\text { kinase }\end{array}$ & $\begin{array}{l}\text { The sphk1 knockout mutant is less } \\
\text { sensitive to ABA; Inhibition of the } \\
\text { enzymatic activity makes cells more } \\
\text { sensitive to LCB-induced PCD }\end{array}$ & Increase in LCBs/LCB-Ps ratio & $\begin{array}{l}\text { Coursol et al. (2003), } \\
\text { Worrall et al. (2008), } \\
\text { Alden et al. (2011), Guo } \\
\text { et al. (2011) }\end{array}$ \\
\hline AtDPL 1 & At1g27980 & $\begin{array}{l}\text { LCB } \\
\text { phosphate } \\
\text { lyase }\end{array}$ & $\begin{array}{l}\text { The knockout mutant has increased } \\
\text { sensitivity to FB1-induced PCD }\end{array}$ & Increase in LCBs/LCB-Ps ratio & Tsegaye et al. (2007) \\
\hline $\mathrm{LOH1}$ & At3g25540 & $\begin{array}{l}\text { Ceramide } \\
\text { synthase } \\
\text { (using VLCFA) }\end{array}$ & $\begin{array}{l}\text { The loh1 knockout mutant shows PCD } \\
\text { associated with } P R \text { gene expression }\end{array}$ & $\begin{array}{l}\text { Accumulation of LCBs and } \\
\text { C16-ceramides, and/or reduction } \\
\text { in VLCFA-ceramides }\end{array}$ & $\begin{array}{l}\text { Markham et al. (2011), } \\
\text { Ternes et al. (2011) }\end{array}$ \\
\hline $\mathrm{LOH} 2$ & At3g19260 & $\begin{array}{l}\text { Ceramide } \\
\text { synthase } \\
\text { (using C16 FA) }\end{array}$ & $\begin{array}{l}\text { Reduction in C16-ceramides; No } \\
\text { obvious phenotype detected so far }\end{array}$ & NA & $\begin{array}{l}\text { Markham et al. (2011), } \\
\text { Ternes et al. (2011) }\end{array}$ \\
\hline $\mathrm{LOH} 3$ & At1g13580 & $\begin{array}{l}\text { Ceramide } \\
\text { synthase } \\
\text { (using VLCFA) }\end{array}$ & $\begin{array}{l}\text { The loh1/loh3 double knockdown } \\
\text { mutant has accumulation of LCBs and } \\
\text { C16-ceramides, but reduction in } \\
\text { VLCFA-ceramides }\end{array}$ & $\begin{array}{l}\text { Mimicking the effect of FB1 } \\
\text { treatment }\end{array}$ & $\begin{array}{l}\text { Markham et al. (2011), } \\
\text { Ternes et al. (2011) }\end{array}$ \\
\hline CERK (ACD5) & At5g51290 & $\begin{array}{l}\text { Ceramide } \\
\text { kinase }\end{array}$ & $\begin{array}{l}\text { The acd5 knockout mutant develops } \\
\text { SA-dependent PCD, and is more } \\
\text { susceptible to } P \text {. syringae but more } \\
\text { resistant to powdery mildew }\end{array}$ & Accumulation of ceramides & $\begin{array}{l}\text { Liang et al. (2003), } \\
\text { Wang et al. (2008) }\end{array}$ \\
\hline FAH1/FAH2 & $\begin{array}{l}\text { At2g34770/ } \\
\text { At4g20870 }\end{array}$ & $\begin{array}{l}\text { Fatty acyl } \\
\alpha \text {-hydroxylase }\end{array}$ & $\begin{array}{l}\text { AtFAHs are required for AtBI-mediated } \\
\text { suppression of PCD in mutant yeast }\end{array}$ & $\begin{array}{l}\text { Complementation of yeast fah } \\
\text { mutant }\end{array}$ & Nagano et al. (2009) \\
\hline IPCS2 (ERH1) & At2g37940 & $\begin{array}{l}\text { Inositol- } \\
\text { phosphoryl- } \\
\text { ceramide } \\
\text { synthase }\end{array}$ & $\begin{array}{l}\text { The erh1 knockout mutant develops } \\
\text { SA-dependent PCD in plants } \\
\text { expressing RPW8 }\end{array}$ & $\begin{array}{l}\text { Accumulation of ceramides with } \\
\text { a trihydroxy LCB and a } \\
\text { non-hydroxylated C16 fatty acid }\end{array}$ & Wang et al. (2008) \\
\hline$A C D 11$ & At2g34690 & $\begin{array}{l}\text { Sphingosine } \\
\text { transfer } \\
\text { protein }\end{array}$ & $\begin{array}{l}\text { The acd11-knockout mutant develops } \\
\text { SA-dependent PCD }\end{array}$ & Failure in sphingolipid transport? & $\begin{array}{l}\text { Brodersen et al. } \\
\text { (2002), Petersen et al. } \\
\text { (2008) }\end{array}$ \\
\hline MIPS1 & At4g39800 & $\begin{array}{l}\text { Myo-inositol } \\
\text { 1-phosphate } \\
\text { synthase }\end{array}$ & $\begin{array}{l}\text { The mips } 1 \text { knockout mutant develops } \\
\text { PCD associated with defense }\end{array}$ & $\begin{array}{l}\text { Ceramide accumulation due to } \\
\text { deficiency in phosphatidylinositol } \\
\text { as substrate for IPCSs }\end{array}$ & $\begin{array}{l}\text { Meng et al. (2009), } \\
\text { Donahue et al. (2010) }\end{array}$ \\
\hline MPK6 & At2g43790 & MAP kinase & $\begin{array}{l}\text { The mpk6 knock out mutant is less } \\
\text { sensitive to FB1 or free LCB (d18:0) } \\
\text { induced PCD }\end{array}$ & $\begin{array}{l}\text { Defective in LCB-triggered } \\
\text { MAPK signaling engaged in } \\
\text { LCB-triggered PCD }\end{array}$ & $\begin{array}{l}\text { Saucedo-Garcia et al. } \\
\text { (2011b) }\end{array}$ \\
\hline Myb30 & At3G28910 & $\begin{array}{l}\text { Transcription } \\
\text { factor }\end{array}$ & $\begin{array}{l}\text { Myb30 positively regulates } \mathrm{HR} \text { and } \\
\text { defense }\end{array}$ & $\begin{array}{l}\text { Activation of genes encoding } \\
\text { components of acyl-CoA } \\
\text { elongase complex required for } \\
\text { VLCFA synthesis }\end{array}$ & $\begin{array}{l}\text { Raffaele et al. (2008), } \\
\text { Canonne et al. (2011) }\end{array}$ \\
\hline
\end{tabular}


rate-limiting step of de novo sphingolipid synthesis (Figure 2). This result provided direct genetic evidence for the conclusion derived from the experiments in which inhibition of SPT by a fungal toxin myriocin alleviated AAL or FB1-induced PCD (Spassieva et al., 2002). That is: the accumulation of LCBs, not the blockage of the de novo sphingolipid biosynthesis per se underlies AAL/FB1-induced PCD. It is worth noting that another more severe mutant allele of $L C B 1, f b r 11-2$ causes the formation of abortive microspores due to cell death of the binucleated microspores, suggesting an essential role of sphingolipid biosynthesis in male gametophyte development (Teng et al., 2008).

\section{ACD5 - a ceramide kinase}

One Arabidopsis mutant with spontaneous accelerated cell death due to a defect in sphingolipid metabolism is acd5 (Greenberg et al., 2000). ACD5 is predicted to encode a ceramide kinase (Liang et al., 2003; Figure 2). Consistently, ceramides as substrates are accumulated at a higher level in acd5 plants compared to wild-type plants (Liang et al., 2003). The authors demonstrated in vitro assays that recombinant ACD5 has ceramide kinase activities and prefers ceramides containing sphingosine with a double bond at position $4\left(\mathrm{~d} 18: 1^{\Delta 4 \mathrm{E}}\right)$ as the LCB moiety than ceramides containing dihydrosphingosine (d18:0; Liang et al., 2003). Recent functional analysis on the rice ACD5 ortholog demonstrated that ceramides induce cell death with similar features in monocots and dicots (Bi et al., 2011). Genetic analyses showed that acd5mediated cell death is SA-dependent and associated with $P R$ gene expression, but acd5 plants were slightly more susceptible to virulent bacterial pathogens (Greenberg et al., 2000; Liang et al., 2003), suggesting that SPI-PCD can be uncoupled from resistance to bacterial pathogens. However, acd5 plants showed apparent enhanced resistance to powdery mildew, which is an obligate biotrophic fungal pathogen (Wang et al., 2008). These seemingly conflicting results probably reflect the differential efficacy of SPI-PCD in defenses against pathogens deploying different mechanisms for pathogenesis.

\section{ERH1 - an inositol-phosphorylceramide synthase}

Additional genetic evidence for ceramide accumulation as a potential trigger of plant PCD in connection with defense came from a genetic screen for mutations enhancing RPW8-mediated $\underline{H R}$ cell death (erh; Wang et al., 2008). RPW8 is an atypical R protein that confers SA-dependent, broad-spectrum resistance to powdery mildew (Xiao et al., 2001, 2005). ERH1 was cloned and found to encode an inositol-phosphorylceramide synthase (IPCS; At2g37940; AtIPCS2), which catalyzes the production of inositolphosphorylceramide (IPC) and diacylglycerol from ceramide and phosphatidylinositol (Nagiec et al., 1997; Denny et al., 2006; Wang et al., 2008; Figure 2). ERH1 was rapidly induced by Psm avrRpm1 (during ETI) and by powdery mildew especially in plants expressing $R P W 8$, and showed elevated expression in plants exhibiting massive spontaneous HR-like cell death due to overexpression of RPW8 (Wang et al., 2008). Loss of AtIPCS2 in erh1 plant containing $R P W 8$ results in significantly higher levels of ceramides and massive HR-like cell death which correlates with transcriptional amplification of RPW8 and elevated level of SA (Wang et al., 2008). There are three IPCS genes in the Arabidopsis genome. AtIPCS2 and the other two homologs (At3g54020, AtIPCS1; At2g29525AtIPCS3) all have been shown to possess IPCS activities (Wang et al., 2008; Mina et al., 2010), with likely differential and overlapping organ/tissue expression in Arabidopsis (Mina et al., 2010), suggesting that there is functional redundancy as well as specialization between these three IPCSs (Mina et al., 2010). Notably, the acd5/erh1 double mutant developed more severe cell death and acd5/erh1/RPW8 plants show lethal cell death, possibly as a consequence of even higher levels of ceramide or its precursor LCBs compared to single mutants (Wang et al., 2008).

\section{ACD11 - a sphingolipid transporter}

The acd 11 mutant provides intriguing evidence linking perturbation of sphingolipid metabolism (transport) with R protein functions in HR. The acd11-knockout (ko) Arabidopsis plants displays lethal cell death. Similar to PCD induced by FB1, acd11-mediated PCD is accompanied with SA-dependent $P R$ gene expression (Brodersen et al., 2002). These phenotypes can be suppressed by mutations in SA-signaling components EDS1 or PAD4 (Brodersen et al., 2002). ACD11 is predicted to encode a protein that is structurally similar to mammalian GLTP which transfers glycosphingolipids (Sasaki, 1985; Malinina et al., 2004). In fact, human GLTP could partially suppress acd11-mediated cell death in Arabidopsis (Petersen et al., 2008). ACD11 was shown in vitro assays to possess activities in transferring sphingosine (d18:1) but not ceramides between membranes (Brodersen et al., 2002). Intriguingly, ACD11 was also shown to have activities in transferring animal SM which has not been detected in plants but structurally similar to plant IPC. Therefore it is possible that physiological substrates of ACD11 may not be limited to sphingosine (Brodersen et al., 2002; Petersen et al., 2008). However, because different ACD11 mutant forms that lost lipid transfer activities toward SM can also rescue the cell death phenotype of acd11, this uncharacterized sphingolipid transfer activity of ACD11 (even if it exists in planta) seems dispensable for PCD regulation. These data hint the importance of transferring sphingosine and other related derivatives by ACD11 to certain subcellular compartments (Figure 2) and suggest that if this step is disrupted, cell death ensues. Consistent with this speculation, Petersen et al. (2009) recently identified four potential ACD11-interacting proteins and all these proteins are associated with membrane fraction, implying that ACD11 is functionally related to membrane trafficking (Petersen et al., 2009).

An alternative hypothesis proposed by the authors is that ACD11 may serve as a "guardee" protein of an intracellular NBLRR protein, as it is the case for RIN4 being the "guardee" of NB-LRR proteins conferring resistance to P. syringae (Axtell and Staskawicz, 2003; Mackey et al., 2003; Marathe and Dinesh-Kumar, 2003). In this regard, the absence of ACD11 may be sensed by the cognate NB-LRR protein, which subsequently triggers PCD (Petersen et al., 2008). The subcellular compartment where ACD11 localizes is currently unknown. Future identification of the exact physiological substrates of ACD11 and the subcellular location where ACD11 functions will be revealing.

Because acd11-mediated cell death has intimate connection with the SA-dependent defense pathway, acd11 was used in a secondary screen for suppressor mutations. Three such suppressor mutations named lazarus 1 (laz1), laz2, and laz5 were isolated 
(Malinovsky et al., 2010; Palma et al., 2010). laz1 is a loss-offunction mutation in At4g38360 encoding a protein showing homology to human tumor suppressor TMEM34 (Akaishi et al., 2007; Malinovsky et al., 2010). Although LAZ1 did not seem to play any role in basal and $R$ gene-dependent resistance to bacteria, it is required for HR manifested during $N B-L R R R$ gene RPS4- and RPM1-mediated resistance to the cognate avirulent P. syringae strains (Malinovsky et al., 2010). This result supports the notion that HR can be uncoupled from bacterial resistance (Clough et al., 2000; Jurkowski et al., 2004; Coll et al., 2010). Intriguingly, another acd11-cell death suppressor is a dominant negative mutation in an RPS4-like NB-LRR gene (LAZ5), which strongly suggests that acd11-cell death engages inappropriate activation of one or more NB-LRR proteins. This finding also lends support to the hypothesis that ACD11 may be a "guardee" of one or more NB-LRR proteins and loss of ACD11 can trigger activation of its guarding NB-LRRs. In addition, the authors further found that a loss of function mutation in a gene encoding a histone lysine methyltransferase SDG8 in the laz2 mutant also suppressed acd11cell death (Palma et al., 2010). More interestingly, the authors showed that SDG8 is required for expression of $L A Z 5$ and probably other $N B-L R R$ genes and that $S D G 8$ is required for basal and $\mathrm{R}$ protein-mediated pathogen resistance (Palma et al., 2010). Collectively, these results on $A C D 11$ and $L A Z$ genes have established an intrinsic connection between dysfunction of sphingolipid metabolism (likely sphingolipid transport) and plant PCD which shares common mechanisms with HR occurring in ETI (Palma et al., 2010).

\section{"DEATH" CONNECTION III: ARABIDOPSIS MUTANTS IDENTIFIED BY REVERSE GENETICS}

Advances in yeast and animal sphingobiology coupled with functional genomics studies of Arabidopsis and other plant species have led to the identification of most candidate genes ( $\sim 30)$ encoding enzymes participating in plant sphingolipid metabolism (Zauner et al., 2010; some are listed in Table 2). As such, a more targeted, reverse genetics approach has become possible to study the various cellular functions of sphingolipids using the Arabidopsis model system. Such studies have further consolidated the findings based on the fungal toxins and genetic mutants obtained in forward genetic screens described above. Here we only introduce three examples.

\section{LCB2 - the other subunit of the serine palmitoyltransferase}

All known eukaryotic SPTs are membrane-associated heterodimers that are composed of subunits encoded by the LCB1 (FBR11) and LCB2 genes (Hanada, 2003). In Arabidopsis, there are two functionally redundant homologous genes ( $L C B 2 a$ and $L C B 2 b$ ) encoding for the LCB2 subunit (Dietrich et al., 2008). While genetic data derived from the fbr11-1 mutant fully support the results from those obtained using fungal toxins (Spassieva et al., 2002; Wispriyono et al., 2002; Shi et al., 2007), there is considerable discrepancy among recent data concerning PCD phenotypes caused by genetic mutations in $L C B 2 a$ and $L C B 2 b$. The Arabidopsis lcb2a-ko mutant is less sensitive to FB1-induced cell death (Saucedo-Garcia et al., 2011b), consistent with the notion that accumulation of LCBs plays a critical role in activation of PCD.
Conversely, Takahashi et al. (2009) showed that overexpression of Nicotiana benthamiana ( $\mathrm{Nb}$ ) LCB2 caused cell death, possibly due to the accumulation of LCBs in the cells with enhanced activity of SPT (Takahashi et al., 2009). However, a study from Gan et al. (2009) showed that silencing the presumable sole $N$. tobaccum $(\mathrm{Nt})$ LCB2 enhanced cell death induced by multiple elicitors including the pro-apoptotic mouse protein Bax, while overexpression of an LCB2 gene from Chinese cabbage Brassica campestris $(B c)$ ssp. chinensis suppressed cell death induced by the same elicitors and disease associated cell death caused by Ralstonia solanacearum in N. tobaccum (Gan et al., 2009). Intriguingly, the ability of $B c L C B 2$ to suppress cell death did not seem to require its function involving SPT activity, suggesting a novel cellular function independent of SPT for BcLCB2. Whether BcLCB2 overexpression or $N t L C B 2$ silencing in $N$. tobaccum alters sensitivity to FB1-induced PCD has not been determined. Nor did the authors test if $B c L C B 2$ overexpression can suppress HR during ETI in Chinese cabbage. Nevertheless, these unexpected observations imply that LCB2 from different plant species may behave differently in heterologous backgrounds and/or that there may be species-specific threshold levels of LCBs for triggering cell death.

\section{LOH1/LOH2/LOH3 - ceramide synthases}

The biochemical function of Asc has not been reported, leaving the precise biochemical nature of AAL-induced PCD and diseaselike symptom in tomato undetermined. A recent elegant study by Markham et al. (2011) has offered an indirect but convincing answer to this question. The authors identified T-DNA mutants for three Arabidopsis Asc homologs, LAG One $\underline{\text { Homolog }} 1$ ( $\mathrm{LOH}$; At3g25540), LOH2 (At3g19260), and LOH3 (At1g13580) based on sequence homology (Markham et al., 2011). They demonstrated that $\mathrm{LOH} 1$ and $\mathrm{LOH} 3$ which encode acyl-CoA-dependent CerSs are responsible for the synthesis of ceramides containing very long-chain (C20-C28) FA (VLCFA), whereas the CerS encoded by $\mathrm{LOH} 2$ is specific for synthesis of ceramides containing C16:0 FAs (Markham et al., 2011; Figure 2). The authors also found that the loh1/loh 3 sesqui-mutant (double knockdown) showed accumulation of LCBs (such as d18:0 and t18:0) and C16:0-ceramides, in addition to a significant reduction in VLCFAceramides (Markham et al., 2011). This alteration of the sphingolipid pattern is similar to that caused by FB1 treatment on wild-type Arabidopsis (Abbas et al., 1994; Markham et al., 2011) and reminiscent of the higher sensitivity of asc/asc tomato plants to AAL-induced PCD (Brandwagt et al., 2000; Spassieva et al., 2002). These observations, together with another report that loh 1 mutant Arabidopsis developed spontaneous HR-like cell death in mature leaves at a late developmental stage (Ternes et al., 2011), and relevant findings in yeast and animals (Guillas et al., 2001; Schorling et al., 2001; Pewzner-Jung et al., 2010; Mullen et al., 2011b), suggest that (i) different isoforms of acyl-CoA-dependent CerSs in higher eukaryotes possess differential preferences on FA substrates, (ii) FB1 selectively inhibits VLCFA-ceramide synthesis in animals and plants, and (iii) accumulation of LCBs and/or accumulation of C16-ceramides, and/or deficiency in VLCFA-ceramides (and possibly accumulation of VLCFAs as substrates) all may contribute to the initiation of PCD. Based on these results, it seems very likely that the higher sensitivity/susceptibility of asc/asc tomato cultivars 
to AAL/A. alternata f. sp. lycopersici is due to reduction of total VLCFA-specific CerS activity as a result of the natural mutation in the Asc ( $L O H 1 / 3-$ like) gene.

\section{SBH1/SBH2 - sphingoid base hydroxylase}

The Arabidopsis genome contains two LCB C-4 hydroxylase genes Sphingoid base hydroxylase1 (SBH1; At1g69640) and SBH2 (At1g14290) for hydroxylation of LCB at 4-position (Figures 1 and 2). sbh1/sbh2 double mutant plants completely lacked trihydroxy LCBs, showed severe dwarfism, and enhanced expression of genes associated with PCD (Chen et al., 2008). In addition, C4hydroxylation seems to be optional in C16-Cer species, but obligatory in C20-C28-Cer species, since the $s b h 1 / s b h 2$ double mutant showed severely decreased proportions of C20-C28-Ceramide species, despite an approximate 2.5 -fold increase in the total content of sphingolipids when compared to the wild-type plants (Chen et al., 2008). These results, together with recent findings that LOH2 accepts both dihydroxy LCBs (d18:0) and trihydroxy LCBs (t18:0) for C16-Ceramide synthesis while LOH1 and LOH3 appear to prefer trihydroxy LCBs for VLCFA-ceramide synthesis (Markham et al., 2011; Ternes et al., 2011) suggest that structural features of the sphingoid base such as hydroxylation (and likely desaturation) also affect the efficacy of the corresponding LCBs and ceramides in regulation of plant growth and development and PCD, as it has been shown for the LCB mediators in stomata closure (Ng et al., 2001).

\section{THE BIOACTIVE SPHINGOLIPIDS AS MODULATORS OF PLANT PCD}

An obvious generalization from studies with AAL and FB1, and genetic analyses with various Arabidopsis mutants is that perturbations of sphingolipid metabolism could lead to plant PCD and that SPI-PCD is intimately connected with the SA-dependent defense signaling pathway. However, the exact bioactive sphingolipids that triggered PCD in most experiments were not definitively characterized. This uncertainty is primarily due to (i) detection of changes of all relevant sphingolipids by sphingolipidomic profiling was difficult in the past and is still not trivial today (Markham et al., 2006; Markham and Jaworski, 2007); and (ii) the sphingolipid metabolic pathway is an interconnected complex "spider" web, perturbation in one step will likely produce an "metabolic ripple effect," leading to an alteration elsewhere in the metabolic pathway (Hannun and Obeid, 2008, 2011). Despite the difficulty, new emerging evidence from recent genetic and biochemical studies (Liang et al., 2003; Shi et al., 2007; Wang et al., 2008; Peer et al., 2010; Alden et al., 2011; Markham et al., 2011; Saucedo-Garcia et al., 2011b), in combination with the data from previous findings with fungal toxins (Abbas et al., 1994, 1995a; Wang et al., 1996a; Brandwagt et al., 2000) support the notion that both free LCBs and ceramides, and their respective phosphorylated forms play a critical role in regulation of plant PCD. These results are also generally in agreement with the findings in the animal system (Obeid et al., 1993; Hannun, 1996; Mullen et al., 2011a).

LCBs AND LCB-Ps: THE FIRST "YIN-YANG" PAIR

A rapid accumulation of endogenous dihydrosphingosine (d18:0), phytosphingosine (t18:0) within hours after AAL or FB1 treatment was correlated with PCD development both in plants and animals (Abbas et al., 1994; Riley et al., 1996; Wang et al., 1996a; Norred et al., 1997; Schmelz et al., 1998). These observations were consistent with the mode-of-action for the fungal toxin AAL and FB1 as inhibitors of acyl-CoA-dependent CerSs and pointed a critical role for LCBs as signaling molecules for PCD. Results from more recent studies using exogenous free LCBs for PCD induction in whole seedlings or localized leaf sections or suspension cultures generally supported this notion (Shi et al., 2007; Takahashi et al., 2009; Saucedo-Garcia et al., 2011b), or to cultured plant cells (Lachaud et al., 2010, 2011; Alden et al., 2011).

FB1 treatment also induces accumulation of phosphorylated forms of LCBs (LCB-Ps) in Arabidopsis (Shi et al., 2007; Markham et al., 2011; Saucedo-Garcia et al., 2011b), suggesting a potential regulatory role for LCB-Ps in modulation of plant PCD. Because LCB-Ps have been shown to suppress PCD in animal cells (Cuvillier et al., 1996; Spiegel et al., 1998; Spiegel and Milstien, 2003), it is possible that LCB-Ps may serve a similar function in plants. Shi et al. (2007) showed that whereas exogenous LCBs could induce ROS production and PCD on leaves of Arabidopsis seedling grown on agar medium, the respective LCB-Ps were incapable of inducing PCD. More importantly, ROS generation and cell death induced by d18:0 were specifically blocked by its phosphorylated form dihydrosphingosine-1-phosphate in a dose-dependent manner, suggesting that the maintenance of homeostasis between a free sphingoid base and its phosphorylated derivative is critical to determining the cell fate (Shi et al., 2007). In support of this notion, affecting the endogenous ratio between LCBs/LCB-Ps via a genetic mutation in the AtDPL gene (At1g27980) encoding the LCB-P lyase (Tsegaye et al., 2007) was found to cause PCD in Arabidopsis leaves, and blocking the conversion of LCBs to LCB-Ps using inhibitors of sphingosine kinase (SphK) promoted PCD induction by LCBs in Arabidopsis cell culture (Alden et al., 2011). Combined, these observations support the existence of a dynamic balance of cellular concentrations of LCBs and LCB-Ps as a rheostat to control cell fate in both plants and animals (Verheij et al., 1996; Hannun and Obeid, 2008; Alden et al., 2011).

However, there is some discrepancy with regard to which LCB species are the primary or more potent bioactive lipid molecules in PCD induction based on exogenous applications. Shi et al. (2007) showed that d18:0, t18:0, or d18:1 all could induced PCD in Arabidopsis seedlings grown on agar medium, d18:0 was less potent than t18:0, consistent with a previous finding that t18:0 displays greater phototoxicity than d18:0 (Tanaka et al., 1993). Recently, however, Saucedo-Garcia et al. (2011b) showed that while d18:0 was a potent inducer of PCD in Arabidopsis seedlings, t18:0 barely induced PCD. The exact cause of these differences is not clear. It may be attributable to the differences in plant growth conditions and ways of LCB application used in these separate studies.

\section{PHYTOSPHINGOSINE (t18:0), THE DEATH SIGNAL FOR HR?}

Despite the correlation between accumulation of LCBs and plant PCD associated expression of SA-dependent defense gene expression, whether LCB accumulation is an intrinsic early step in the activation of HR during ETI has not been investigated until recently. By using a sphingolipidomic profiling approach, Peer 
et al. (2010) found that while Arabidopsis leaves accumulate the t18:0 as early as $1 \mathrm{~h}$ after inoculation with either virulent or avirulent strains of $P$. syringae pv. tomato (Pst), only leaves inoculated with the avirulent strain showed a fast and sustained increase $(\sim 20 \times)$ of $\mathrm{t} 18: 0$ from 1 to $24 \mathrm{~h}$ post-inoculation (hpi; Peer et al., 2010), which corresponds to the manifestation of HR from 8 to 15 hpi (Kiedrowski et al., 1992). It is important to note that there was no significant accumulation of d18:0 in both cases (Peer et al., 2010). By using mutant sbh1-1 (in which generation of t18:0 from d18:0 through C-4 hydroxylation is compromised), the authors also demonstrated that the pathogen-triggered t18:0 increase most likely resulted from de novo synthesis from d18:0 (Peer et al., 2010). Therefore, this study suggested that $\mathrm{t}$ 18:0 rather than $\mathrm{d} 18: 0$ is a positive regulator of HR. However, how pathogen perception triggers accumulation of t18:0 is not known, and whether accumulation of t18:0 plays a role in restricting bacterial growth during ETI also remains to be determined. Intriguingly, Takahashi et al. (2009) showed that expression of the NbLCB2 gene is induced to higher levels in leaves of $N$. benthamiana after inoculation with the nonhost pathogen Pseudomonas cichorii. Resistance of N. benthamiana against $P$. cichorii was compromised in NbLCB2- and NbLCB1silenced plants, and in wild-type plants whose SPT activity was inhibited by myriocin (Takahashi et al., 2009). These results suggest that de novo biosynthesis of sphingolipids (perhaps transient accumulation of LCBs such as t18:0) is necessary for the non-host resistance of $N$. benthamiana against $P$. cichorii.

\section{CERAMIDES AND CERAMIDE-1-PHOSPHATES: THE SECOND "YIN-YANG" PAIR}

Ceramides have long been known to induce PCD in both plant and animals (Obeid et al., 1993; Hannun, 1996; Gilchrist, 1997; Townley et al., 2005). Genetic data from the acd5 and erh1 Arabidopsis mutants also support the notion that ceramide accumulation triggers PCD in plants (Liang et al., 2003; Wang et al., 2008). Recent studies in animals suggest that bioactive ceramides constitute a hub for regulation of multiple cellular processes and particularly act as triggers of apoptosis and autophagy in various cell lines (Nikolova-Karakashian and Rozenova, 2010; Bedia et al., 2011; Hannun and Obeid, 2011).

In contrast, phosphorylated ceramides have been shown to suppress plant PCD. For example, ceramide-1-phosphate (Cer-1-P) was able to partially abrogate the cell death of Arabidopsis protoplasts induced by C-2 ceramide (Liang et al., 2003). Given that $A C D 5$ encodes an active ceramide kinase, this observation suggests that like in the case of LCBs and LCB-Ps, an appropriate balance between ceramide and Cer-1-P via the ceramide kinase and phosphatase activities is crucial for cell and tissue homeostasis. Switching this balance toward accumulation of ceramide may trigger PCD. This is reminiscent of the findings in animals that Cer-1-P and Ceramide are two antagonistic molecules in regulation of cell fate (Gomez-Munoz, 2004, 2006; Hinkovska-Galcheva and Shayman, 2010). One possible mechanism explaining Cer1-P's suppression of ceramide-induced PCD in animals is that Cer-1-P inhibits SPT activity, thereby inhibiting accumulation of ceramide from de novo synthesis (Granado et al., 2009). It will be interesting to see if Cer-1-P also inhibits SPT and suppress ceramide accumulation in plant cells.

\section{MANY CERAMIDES, WHICH ARE MORE POTENT IN TRIGGERING PCD?}

There are many structural variants of ceramides with differential cellular functions (Hannun and Obeid, 2011). For example, ceramide hydroxylation is important for its efficacy in cell death induction. Townley et al. (2005) reported that ceramides containing non-hydroxy short fatty acyl chain, but not ceramides with 2-hydroxylation, induced cell death of Arabidopsis suspension cultures (Townley et al., 2005). Recently, Nagano et al. (2009) identified two putative 2-hydroxylase (At-FAH) homologs in Arabidopsis (Nagano et al., 2009). The authors showed that the Arabidopsis Bax inhibitor-1 (AtBI-1), which functions to attenuate plant PCD induced by an array of elicitors including FB1 (Watanabe and Lam, 2006, 2008), interacts with AtFAHs via cytochrome b5 in plant cells (Nagano et al., 2009). They further showed that the yeast FAH1 gene (which can be functionally complemented by AtFAHs) is required for suppression of cell death mediated by overexpression of AtBl-I in yeast and this suppression is associated with increased levels of 2-hydroxy FAs. Based on these observations, the authors proposed that AtBI-1 may work with AtFAHs and cytochrome B5 to accelerate the FA 2-hydroxylation of ceramides, thereby regulating the levels of non-hydroxylated and 2-hydroxylated ceramides, which in turn modulate cell death in plants (Nagano et al., 2009). However, genetic evidence for a relevant role of the AtFAH genes in Arabidopsis has yet to be provided.

The acyl-CoA chain length in ceramides has also important functional implications for ceramides. Recent work on three Arabidopsis acyl-CoA CerSs showed that LOH1 and LOH3 prefer VLCFA substrates while LOH2 prefers short chain (C16) FAs (Markham et al., 2011; Ternes et al., 2011). Accumulation of free LCBs (d18:0 and t18:0) and/or ceramide species with C(16) FA in loh1 mutant was thought to be the trigger of PCD (Ternes et al., 2011). Given the VLCFA preference for LOH1, it seems also possible that reduction of VLCFA-ceramides and/or accumulation of the VLCFA substrates may also contribute to PCD in loh1 mutant. As VLCFA-ceramides are selectively engaged in vesicle trafficking (Roudier et al., 2010; Markham et al., 2011) and lipid raft formation (Ohno et al., 2010; also see later text), it is conceivable that depletion of VLCFA-ceramides may cause serious defect in membrane organization, resulting in cell death.

Given that LCBs and ceramides are metabolically connected, these lipid molecules and their phosphorylated form may work together to control PCD. For example, Cuvillier et al. (1996) showed that S1P can suppress ceramide-induced PCD in mammalian cells. We envision this cross regulation may also occur in plants.

It is important to point out that the physiological concentrations of some bioactive sphingolipids (the free LCBs in particular) may be extremely low and therefore a very small increase, even below the technical detection limits, could trigger signaling via actions on their cognate protein targets. As a corollary to this, it is also possible that large, measurable increases in other LCBs may just be a metabolic reflect of the imbalance created by the rise of the original messenger LCB. Thus, cautions must be exercised when analyzing a cause-effect relationship from simple correlations between phenotypes and levels of major sphingolipids.

Finally, in addition to LCBs and ceramides, the more complex sphingolipids (GIPCs and GlcCERs) might also serve signaling 
roles in plant PCD. However because they are major structural components of plant cell membranes and have at least $10 \times$ higher levels than free LCBs and ceramides in plant cells (Markham et al., 2006; Markham and Jaworski, 2007), it is more difficult to assess the contribution of these complex ceramides in plant PCD due to the difficulty in detecting subtle spatiotemporal changes of these compounds that may provide signals for PCD.

\section{POTENTIAL CONNECTIONS WITH OTHER SIGNALING PATHWAYS FOR PLANT PCD AND DEFENSE}

$\underline{\text { VLCFAs }}$ are also required for the biosynthesis of the plant cuticle that is critical for plant defense as a physical barrier and a signaling platform (Xia et al., 2009, 2010). It has also been reported that perturbation of VLCFA synthesis and metabolism in the leaf epidermis of Arabidopsis causes PCD of trichome cells (Reina-Pinto et al., 2009). Thus the VLCFA pathway may impact plant PCD and defense via both the sphingolipid metabolism and the synthesis of plant cuticle. Raffaele et al. (2008) recently found that four genes encoding enzymes forming the acyl-CoA elongase complex required for synthesis of VLCFAs appear to be putative targets of Myb30 (Raffaele et al., 2008), a transcription factor acting as a positive regulator of SA-dependent HR and resistance (Vailleau et al., 2002; Raffaele et al., 2006), thus linking the VLCFA synthesis pathway with HR and plant defense. The authors proposed that Myb30 modulates HR via VLCFAs by themselves, or VLCFA derivatives, as cell death messengers in plants (Raffaele et al., 2008). Given that VLCFAs are substrates for synthesis of ceramides by LOH1 and LOH3, HR-like cell death in the loh1 knockout plants (Ternes et al., 2011) may partially result from accumulation of VLCFAs. A connection between VLCFAs and plant defense is further supported by a recent study in which Canonne et al. (2011) found that a bacterial effector protein XopD specifically targets Myb30, resulting in inhibition of the transcriptional activation of MYB30, VLCFA-related target genes and suppression of Arabidopsis defense. This finding, together with the earlier work from the same group, suggests that bacterial pathogens target and suppress host VLCFA biosynthesis and consequently impact VLCFA-ceramide levels in plants, thereby suppressing host defense. Direct targeting of sphingolipid metabolism by any pathogen effector protein for suppression of HR and/or defense, though expected, has not been reported.

Phosphatidylinositol as substrate for synthesis of more complex phosphoinositides and IPCs provide the metabolic connection between the two pathways. Consistently, mutant plants lacking myo-inositol 1-phosphate synthase 1 (MIPS1) exhibited PCD and enhanced basal resistance to pathogens, which was accompanied by elevated ceramides and hydroxyceramides (Meng et al., 2009; Donahue et al., 2010). This phenotype may be due to a reduction of IPCS activity as a result of a shortage of phosphatidylinositol as substrate for IPCSs, thus mimicking erh1 (atipcs2)-conditioned PCD (Wang et al., 2008). In addition, mips1 and higher order mutants with genetic depletion in two or more of the MIPS genes also show defects in membrane trafficking (Chen and Xiong, 2010; Luo et al., 2011). Moreover, phosphoinositides are also known to participate in transport of sphingolipids, apart from their direct metabolic connections with sphingolipids (e.g., sharing phosphoinositol source; Breslow and Weissman, 2010). One notable example is that the mammalian ceramide transport proteins
CERT and FAPP2 require direct binding to phosphatidylinositol4-phosphate (PI4P) for their function in ceramide transport (Hanada et al., 2003; D'Angelo et al., 2007). Because loss of ACD11 (a sphingolipid transporter) triggers PCD and defense gene expression in plants (Brodersen et al., 2002), it might be possible that a defect in PI4P biosynthesis may impact ceramide transport, leading to PCD. Another example is that phosphatidic acid (PA) binds to SphKs in Arabidopsis and stimulates their activities in phosphorylating (phyto)sphingosine to generate (phyto-)S1P (Guo et al., 2011). Since S1P is known to regulate ABA-dependent stomatal apertures via the heterotrimeric G-protein alpha-subunit GPA1 (Coursol et al., 2003, 2005) and suppress plant PCD (which is often SA-dependent) induced by accumulation of phytosphingosine (Shi et al., 2007; Alden et al., 2011), the PA-SphK interaction may constitute one of the regulatory mechanisms underlying the complex interplay between the ABA pathway and the SA pathway (Adie et al., 2007; Yasuda et al., 2008; Grant and Jones, 2009).

Nitric oxide (NO) and ROS are implicated in plant immunity (Asai et al., 2010). Whereas ROS production was shown in many cases to precede SPI-PCD (Townley et al., 2005; Shi et al., 2007; Saucedo-Garcia et al., 2011a), the connection between NO generation and SPI-PCD is rarely investigated. Wang et al. (2007) found that generation of NO is required for elicitation of plant defense response in Taxus yunnanensis cell culture by cerebroside, a glycosphingolipid derived from a fungus. Inhibition of NO synthase activity partially blocked the cerebroside-induced $\mathrm{H}_{2} \mathrm{O}_{2}$ production and cell death, suggesting an essential signaling role for $\mathrm{NO}$ in SPI-PCD (Wang et al., 2007). More recently, Cantrel et al. (2011) showed that NO negatively regulates the formation of Phyto-S1P and Cer-1-P, two phosphorylated sphingolipids that are transiently synthesized upon chilling. Because Phyto-S1P and Cer-1-P counteract with t18:0 LCBs and ceramides in PCD induction in plants (Liang et al., 2003; Shi et al., 2007), it remains interesting to determine if NO production generally occurs in SPI-PCD and whether $\mathrm{NO}$ regulates $\mathrm{HR}$ via this mechanism.

\section{MPK6, THE FIRST CHARACTERIZED PROTEIN TARGET OF BIOACTIVE SPHINGOLIPIDS FOR PLANT PCD AND DEFENSE}

Since the identification of protein kinase $C$ as the first target of sphingosine in mammalian cells (Hannun et al., 1986), bioactive sphingolipids have been shown to target many proteins and regulate their cellular functions in yeast and animals (reviewed by Hannun and Obeid, 2008). Genetically, SPI-PCD has been shown to engage several essential components of immunity such as EDS1, PAD4, and SA (Asai et al., 2000; Greenberg et al., 2000; Brodersen et al., 2002; Wang et al., 2008). However, despite the strong genetic connection, no direct protein target of bioactive sphingolipids for SPI-PCD and defense has been characterized in plants. A recent report by Saucedo-Garcia et al. (2011b) may represent a breakthrough. In this study, the authors identified mitogen-activated protein kinase 6 (MPK6) to be a potential direct protein target downstream of LCBs in the signal transduction leading to cell death. Their conclusion was supported by several lines of evidence: (i) MPK6 as a kinase is rapidly ( $\sim 15 \mathrm{~min}$ ) activated by exogenously added FB1 and d18:0 or t18:0; (ii) the mpk6 Arabidopsis mutant has significantly reduced sensitivity to FB1-induced PCD despite accumulation of endogenous LCBs or PCD induced by application 
of the exogenous d18:0 (which suggests MPK6 is downstream of LCBs); and (iii) mpk6 mutant seedlings seemed to be partially compromised in ETI (showing more bacterial growth than wildtype and $L c b 2 a$ ). Earlier published work showed that (i) MPK6 is a known component of the MAP kinase signaling module of PTI (e.g., flagellin-triggered immunity; Asai et al., 2002; Pitzschke et al., 2009), (ii) MPK6 also contributes to ETI and SA-dependent basal resistance (Zhang et al., 2000; Desikan et al., 2001; Menke et al., 2004), (iii) MPK6 is targeted and inhibited by HopA1, an effector protein of P. syringae (Zhang et al., 2007), and (iv) t18:0 is rapidly accumulated before the onset of HR and ETI (Peer et al., 2010). Thus, MPK6 appears to be a molecular hub that may integrate signals from PTI and ETI and is, not surprisingly, targeted by pathogens for enhancing virulence. However, how ETI may be connected to PTI via MPK6 is not understood. In this context, the new finding by Saucedo-Garcia et al. (2011b), seems to suggest that plants develop ETI in part through reinforcing PTI, and activation of MPK6 by bioactive free LCBs de novo synthesized in infected tissues during early signaling of ETI may act as a "bridge" connecting the ETI and PTI pathways. It is interesting to note that OsMAPK6, the rice ortholog of MPK6 is also activated during immune response induced by pathogen-specific sphingolipids which presumably function as PAMPs (Umemura et al., 2000; see next section for details), and FB1 also increases MPK activity in animal cells (Wattenberg et al., 1996; Pinelli et al., 1999).

Whether LCBs activate MPK6 directly via binding to MPK6 or indirectly via activation of a kinase(s) upstream of MPK6 remains to be determined. Also, because the mpk6 mutant is compromised in $R$-gene resistance, but $l c b 2 a$ is not (Saucedo-Garcia et al., 2011b), MPK6 seemed to be (partially) functional in $l c b 2 a$ plants. This implies that there may be sufficient LCBs in the $l c b 2 a$ mutant (resulting from ceramide catabolism, for example) that allows (partial) activation of MPK6 or MPK6 may be activatable by other molecules during infection. It will be interesting to test if $L c b 2 a$ and mpk6 single (or myriocin-treated wild-type) and $l c b 2 a / m p k 6$ double mutant plants are compromised in HR and resistance to further establish the link between LCB accumulation, MPK6 activation and HR.

\section{REGULATION OF BIOACTIVE SPHINGOLIPIDS DURING DEFENSE: WHEN AND WHERE TO DIE?}

It is conceivable that as potential endogenous danger signals for PCD in connection with defense gene expression, levels of LCBs and ceramides must be tightly regulated in plant cells. Unfortunately, except for one report showing a rapid and transient elevation of t18:0 that correlates with ETI (Peer et al., 2010), there is no other study on spatiotemporal dynamics of these bioactive sphingolipids in cells/tissues developing HR, and how it may be regulated. One possible regulatory mechanism involves manipulation of key metabolic enzymes listed in Table 2 at the transcriptional and/or (post)-translational levels to produce a rapid local change in levels of relevant bioactive sphingolipid, thereby allowing controlled PCD. Several genes ( LCB1, LCB2, ACD5, ERH1, etc) encoding enzymes in the sphingolipid metabolic pathway have been shown to be induced by pathogen infection (Liang et al., 2003; Wang et al., 2008; Gan et al., 2009; Takahashi et al., 2009), supporting this speculation. Further, there is likely tissue/organ-specific regulation of the abundance of the bioactive sphingolipids, owing to the spatiotemporal distribution of relevant metabolic enzymes and their regulators. For example, different ceramidases degrade ceramides by hydrolyzing the $N$-acyl linkage between the LCB and FA moieties, thereby regulating the dynamic balance of ceramides, LCBs and their phosphate derivatives in a tissue/cell-specific manner in animals (Spiegel and Milstien, 2003; Hannun and Obeid, 2008; Mao and Obeid, 2008). Although little is known about plant ceramidases in general (Pata et al., 2008; Yu et al., 2011), distinct isoforms differing in their subcellular localization and substrate specificities should exist in plant cells (Pata et al., 2010). Orm proteins as key regulators of sphingolipid homeostasis in yeast and animals (Breslow et al., 2010; Han et al., 2010) probably function similarly in plants to exert feedback regulation. In this regard, it will be interesting to test if the two Orm-like genes in Arabidopsis (AT1G01230 and AT5G42000) are subject to regulation by pathogen signals.

\section{SPHINGOLIPIDS AS POTENTIAL PAMPS FOR TRIGGERING PLANT IMMUNITY?}

As described above, bioactive sphingolipids act as danger signals to activate PCD with defense gene expression in plants. Interestingly, pathogen-specific sphingolipids have also been found to elicit immune responses in rice. It was reported that cerebrosides A, and C (categorized as glycosphingolipids) from Magnaporthe oryzae induce HR and defense in rice plants (Koga et al., 1998; Umemura et al., 2000). Treatment of rice leaves with cerebroside $\mathrm{A}$ induced the accumulation of antimicrobial compounds (phytoalexins), PCD, and increased resistance to subsequent infection by compatible pathogens. While the degradation products of cerebroside A showed no elicitor activity (Koga et al., 1998), ceramides prepared from the cerebrosides by removal of glucose also showed the elicitor activity (Umemura et al., 2000). It was further found that the methyl group at C-9 and the $4 \mathrm{E}-$ double bond in the sphingoid base moiety of cerebroside A and $\mathrm{C}$ are the key elements determining the elicitor activity of these compounds (Koga et al., 1998). Umemura et al. (2004) also detected similar cerebroside A, B, and C in several soil-borne phytopathogens, such as Fusarium, Pythium, and Botrytis and found that these sphingolipids act as non-race-specific elicitors of defense in many different plant species (Umemura et al., 2004). How these pathogen derived cerebrosides induce defense response is currently unknown. There are two possible mechanisms. First, these cerebrosides or their ceramide metabolites may interfere sphingolipid metabolism of host plants, causing SPI-PCD just as exogenous free ceramides or LCBs. The other possibility is that these pathogenspecific lipids are recognized by host plants as PAMPs by immune receptor protein(s) at the plasma membrane, thereby inducing immune response. Arguing for the second mechanism, Kurusu et al. (2011) recently showed that pathogen-specific sphingolipids induced $\mathrm{Ca}^{2+}$ signaling, MAPK activation and ROS production in cultured rice cells in a similar manner as oligosaccharide PAMPs (Kurusu et al., 2011). However, since both a rapid increase of $\mathrm{Ca}^{2+}$ concentration and production of ROS were also thought to be involved in early signaling for plant PCD induced by free LCBs or ceramides (Shi et al., 2007; Xiong et al., 2008; Lachaud et al., 2010; Saucedo-Garcia et al., 2011a), definitive evidence (i.e., 
identification of the receptor for fungal sphingolipid elicitors) for the second mechanism has yet to be provided.

It is interesting to note that the rice ortholog of AtMKP6, OsMAPK6, has been shown to be post-translationally activated in a rice cell culture by cerebroside A (Lieberherr et al., 2005). Further, the expression of OsMAPK6 is required for defense activation in rice (Lieberherr et al., 2005), suggesting that MPK6-specified MAPK cascade is a conserved signaling module in sphingolipidtriggered defense in both dicots and monocots. More interestingly, genetic analyses showed that the heterotrimeric G-protein alphasubunit is required for activation of a rice Rop GTPase (OsRac1; Suharsono et al., 2002), which in turn acts upstream of OsMAPK6 for defense activation by the sphingolipid elicitor (Lieberherr et al., 2005). Given that S1P-mediated ABA signaling in Arabidopsis requires the heterotrimeric G-protein alpha-subunit (Coursol et al., 2003), it seems possible that some fungus-specific sphingolipids or plant endogenous LCBs may target the heterotrimeric G-protein for eliciting MAPK-dependent signaling leading to defense, whereas phosphorylated LCB (S1P) may target the same G-protein to elicit ABA signaling leading to stomatal closure. Thus the complex crosstalk between SA-signaling and ABA-signaling may result from the interplay between LCBs and phosphorylated LCBs via the G-protein as an early step of the two signaling pathways.

\section{SPHINGOLIPIDS AND LIPID RAFTS IN PLANT IMMUNITY}

One distinct feature of ceramides and more complex sphingolipids as structural components of cell membranes is that they induce an increase in molecular ordering in phospholipid bilayers, which ultimately leads to lateral phase separation and formation of sphingolipid-enriched domains (Stancevic and Kolesnick, 2010). These microdomains or lipid rafts refer to dynamic nanoscale assemblies $(10-200 \mathrm{~nm})$ in cell membranes that are enriched for sphingolipids, sterol, and glycosylphosphatidylinositol (GPI)anchored proteins (Parton and Hancock, 2004; Lingwood and Simons, 2010). The lipid rafts provide a platform for sorting proteins to the cell surface, organize (compartmentalize) functionally relevant proteins such as receptors and signaling molecules at the cell membrane to facilitate detection of external stimuli, initiation, and amplification of signaling processes (Lingwood and Simons, 2010; Stancevic and Kolesnick, 2010; Vieira et al., 2010). Recent advanced imaging and biochemical analyses have further demonstrated the existence of lipid rafts in eukaryotic cell membranes (van Zanten et al., 2009, 2010; Morris et al., 2011).

Studies in the animal field have demonstrated that immune receptors and components of their signaling cascades are spatially organized and that sphingolipids function as key organizing elements in the formation of lipid rafts (reviewed by Dykstra et al., 2003; Lingwood and Simons, 2010; Fessler and Parks, 2011). For example, lactosylceramide (LacCer)-enriched microdomains may form supramolecular complexes with other immune receptors on the plasma membrane for phagocytosis of non-opsonized microorganisms, including bacteria and yeast, and consequently implicated in induction of defense response including ROS production and phagocytosis (Yoshizaki et al., 2008).
Although there are only a few relevant studies in plants, increasing evidence suggest that microdomains also exist in the plant plasma membrane. Recent quantitative proteomic analyses showed that proteins especially GPI-anchored proteins are over-represented in the sphingolipid-sterol enriched, detergentresistant membrane (DRM) prepared from Arabidopsis cells (Borner et al., 2005; Kierszniowska et al., 2009; Carmona-Salazar et al., 2011). Proteins with signaling functions, such as receptor kinases (such the PAMP receptor FLS2), G-proteins, and calcium signaling proteins, were identified as variable members in plant lipid rafts (Kierszniowska et al., 2009). Following PAMP (flg22) treatment, there were rapid and profound changes in DRM protein composition, prominently affecting proton ATPases and receptor-like kinases, including FLS2 (Keinath et al., 2010). These observations, coupled with the finding that there is dynamic degradation of FLS2 via endocytosis upon PAMP perception (Robatzek et al., 2006) suggest that FLS2 and likely other PAMP receptors functions in plasma membrane microdomains.

The focal accumulation of the barley ROR2 syntaxin and the MLO protein to the penetration site of the barley epidermal cells following attack from Blumeria graminis f. sp. hordei (the fungus causing powdery mildew in barley) also suggest that these proteins are recruited to a pathogen-triggered plasma membrane microdomains (Bhat et al., 2005). In uninfected barley epidermal cells, MLO-YFP and YFP-ROR2 are both found at the plasma membrane, at 10-14 hpi, these fluorescently tagged proteins independently accumulate beneath attempted fungal penetration sites. Similar focal accumulation was also seen for PEN3, an ABC transporter required for penetration resistance against non-adapted fungal pathogens (Stein et al., 2006). Given that the ROR2/PEN1 syntaxin is also required for penetration resistance (Collins et al., 2003; Kwon et al., 2008), the formation of plasma membrane microdomains may reflect the host defense response that is effective in halting non-adapted pathogens but overcome by welladapted aggressive pathogens. Alternatively, this pattern of focal accumulation might be part of a process leading to the establishment of a functional domain enabling pathogens' avoidance from the host's immune response and allowing host cell invasion (Bhat et al., 2005).

Plant intercellular bacterial pathogens may also target host plasma membrane microdomains for delivery of their effector proteins via endocytosis. Racape et al. (2005) showed that the effector protein PopA from $R$. solanacearum had a high affinity for sterols and sphingolipids in vitro and that it required $\mathrm{Ca}^{2+}$ for both lipid binding and oligomerization, suggesting that PopA is part of a system that aims to attach the host cell plasma membrane and to allow molecules cross this barrier (Racape et al., 2005). In addition, a recent study showed that remorins (a group of plant-specific proteins implicated in antiviral defense and plant-rhizobium symbiosis) may be localized to plasma membrane microdomains whereby they may serve as scaffold proteins in the lipid rafts during early signaling events (Jarsch and Ott, 2011).

\section{SPHINGOLIPIDS AND POLARIZED TRAFFICKING IN PLANT IMMUNITY}

The concept of microdomain/lipid raft encompasses two mechanistically related cell biological events: polarized/targeted 
membrane/protein trafficking and subcompartmentalization of cellular processes in cell membranes. Like in animals, immune responses in plants also exhibits obvious polarity. One of the first subcellular responses of plants upon detection of plant pathogens in the cell surface is the reorganization and polarization of the cytoskeleton to the site of attack (Schmelzer, 2002; Hardham et al., 2007), which likely prepares plant cells for directional transport of antimicrobial chemicals to the infection site. The finding that NPR1, a central regulatory protein downstream of SA, also controls the expression of the protein secretory pathway genes (Wang et al., 2005) is consistent with this notion. The existence of targeted defense at the subcellular level is more evident in the case of fungal invasions. A rapid deposition of callose $(\beta$ 1,3-glucan) to the fungal penetration site, which leads to the formation of a papilla (i.e., local cell wall-apposition) has long been observed during plant-fungal interactions (Aist, 1976; Israel et al., 1980; Nishimura et al., 2003). Recent identification of membrane trafficking components including the SYP121-SNARE complex (Collins et al., 2003; Assaad et al., 2004; Kwon et al., 2008) and a small GTPase (ARFA1b/1c; Bohlenius et al., 2010) involved in deposition of callose to papillae demonstrated that there is extensive polarized trafficking in the invaded cell for deposition of callose and other antimicrobial chemicals to the site of infection. Specific targeting of the Arabidopsis powdery mildew resistance protein RPW8.2 to the extrahaustorial membrane (EHM) - the host-pathogen interface, represents an exquisite targeted membrane/protein trafficking mechanism evolved in plants for defense against numerous haustorium-forming pathogens including powdery mildew and rust fungi and fungus-like oomycetes (Wang et al., 2009). It can be expected that more host proteins are specifically or preferentially targeted to the EHM during the plant-haustorium interaction. Thus, the finding that RPW8.2 is specifically targeted to the EHM has the following two general implications.

First, plants must have evolved an EHM-targeted membrane/protein trafficking pathway for delivering EHM-resident proteins like RPW8.2 to the EHM. Central to this trafficking mechanism is probably the formation and sorting of the special vesicles carrying the target protein as cargo at the Golgi apparatus. Studies in yeast and animals indicate that ceramides are synthesized at the ER and then transferred and converted to more complex ceramides in the Golgi apparatus where they are processed further and sorted for transport to their final destinations (Hanada et al., 2003; Klemm et al., 2009). It is thought that the asymmetric distribution of sphingolipids themselves in various membrane subcompartments may be inherently coupled with the polarity of membrane/protein trafficking (Futerman, 2007). Whether ceramide and more complex sphingolipids are involved in RPW8.2 vesicle formation, sorting and trafficking to the EHM has not been determined. A recent elegant study by Markham et al. (2011) provided insight into the role of sphingolipids in polarized protein trafficking. The authors showed that reduction of VLCFA-ceramide levels by FB1 treatment or genetic depletion of $\mathrm{LOH} 1 / \mathrm{LOH} 3$ caused selective aggregation of the plasma membrane auxin carriers AUX1 and PIN1 in the cytosol, which correlated with auxin-dependent inhibition of lateral root emergence (Markham et al., 2011). An additional study by Aubert et al.
(2011) detailing the effects of FB1 on the cell morphodynamics and changes in the polar localization of PIN1 in tobacco BY-2 cells highlights the importance of sphingolipids in cell growth and establishment of cell polarity in higher plant cells (Aubert et al., 2011). These findings, together with earlier studies that VLCFA synthesis is involved in membrane trafficking (particularly polar auxin transport) and developmental patterning (Zheng et al., 2005; Roudier et al., 2010), strongly suggest that VLCFAsphingolipids define a trafficking pathway(s) engaged for polarized trafficking of the auxin transport protein cargoes (Markham et al., 2011). Thus it will be interesting to see if VLCFA-sphingolipids are also required for targeting RPW8.2 to the EHM. Notably, loss of IPCS2 (in erh1) induced extensive HR-like cell death in plants expressing RPW8.2 (Wang et al., 2008). It is possible that the HR-like cell death is caused by less efficient transport of RPW8.2 from the Golgi network to the EHM due to reduction of certain (G)IPCs species in the Golgi apparatus, resulting in accumulation of defense-competent RPW8.2 in protein aggregates, which in turn triggers SA-dependent HR-like cell death. Co-localization of IPCS2 and RPW8.2 (Wang et al., 2008) at the trans-Golgi network (TGN) further suggests that (G)IPCs synthesized by IPCS2 at the Golgi may be recruited to the RPW8.2 vesicles at TGN, similarly to the situation where SM is synthesized in the Golgi complex and sorted from the TGN into vesicular carriers for transport to the plasma membrane in animal cells (Shevchenko and Simons, 2010). Although we did not see obvious reduction of RPW8.2-YFP's localization to the EHM in erh1 plants compared to the wild-type (thus implying functional redundancy among the three IPCSs), we observed a significant reduction in EHMlocalization for RPW8.2-YFP after FB1 treatment (Zhang and Xiao, unpublished data). Because the Arabidopsis ipcs $1 / 2$ double mutant is lethal, which suggests an essential function of (G)IPCS in plant growth and development (Xiao, unpublished data), definitive characterization of a potential role of (G)IPCs in RPW8.2's targeting to the EHM requires inducible and/or spatiotemporal depletion of IPCSs.

The second implication from specific localization of RPW8.2 is that the membrane and protein composition of the EHM must be significantly different from the plasma membrane. Indeed, none of the eight plasma membrane proteins examined in Arabidopsis cells containing the fungal haustorium was found at the EHM (Koh et al., 2005). One possibility is that the EHM may contain a different set of selected species of sphingolipids, which is required for the formation of microdomains for accommodating defense proteins such as RPW8.2 for onsite activation of defenses including ROS production (Wang et al., 2009). Our observation that initial EHM-targeted RPW8.2-YFP is found in punctate spots at the EHM supports this possibility (Figure 3). In this regard, it is interesting to note that a tobacco NADPH oxidase subunit NtrbohD has been shown to present in the DRM fraction enriched for lipid rafts (Lherminier et al., 2009), suggesting that the NADPH oxidase protein complex may localize to membrane microdomains. Equally possible is that pathogens (haustoria) may modify and exploit the special features of the EHM to send their effector proteins across the interface. Recent exciting findings from the Tyler group showed that RxLR-containing effectors from oomycete pathogens bind phosphatidylinositol 3-phosphate 


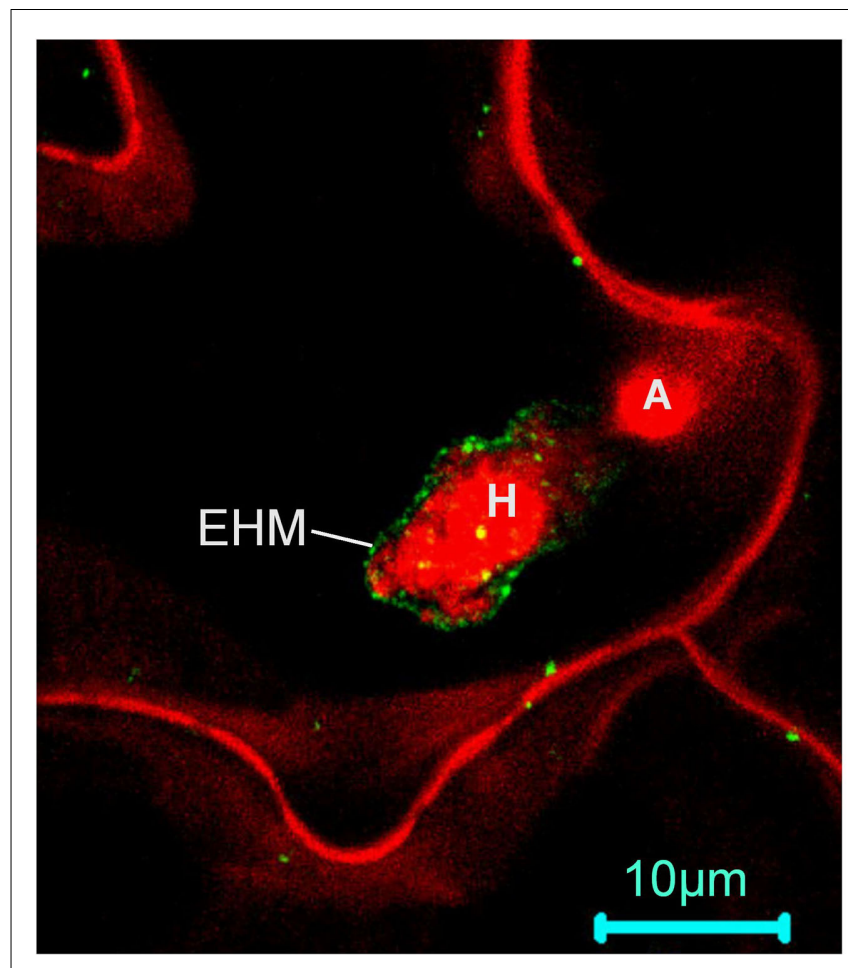

FIGURE 3 | RPW8.2 may be targeted to and function at microdomains of the extrahaustorial membrane (EHM) in Arabidopsis. A confocal image from a Z-stack projection showing that RPW8.2:YFP (green) is initially found in discrete punctate spots in the EHM at $\sim 18 \mathrm{~h}$ after inoculation with powdery mildew before forming a relatively more homogenous distribution in the next 4-6 h Mang et al., 2009). The fungal structure and the host plasma membrane are stained red by propidium iodide. $H$, haustorium; $A$, appressorium.

(PI3P) for host entry (Kale et al., 2010). Because phosphoinositides are known to be present in lipid rafts as signaling molecules (Allen et al., 2007; Vieira et al., 2010), it can be hypothesized that PI3P is enriched in the extracellular leaflet of the EHM, possibly in microdomains, and binding of PI3P anchors RxLR-effectors to the EHM and the effectors then enter the host cell via endocytosis. In animals, various types of intracellular pathogens exploit the sphingolipids and/or other components in the host cell membrane microdomains for host cell entry and establishment of a protected niche within the host (Hartlova et al., 2010; van Der Meer-Janssen et al., 2010). Thus it seems likely that sphingolipidsenriched lipid rafts may provide nanoscale microdomains in the plant-pathogen interfacial membrane for host defense as well as effector entry. Because polarized/targeted trafficking also occur at the interfacial membrane between legume-rhizobium and plantmycorrhiza during their symbiotic interactions (Pumplin and Harrison, 2009; Wang et al., 2010), similar situations may occur in these interfaces.

\section{CONCLUSION AND FUTURE PERSPECTIVE}

Putting all discussed together, we propose in Figure 4 three major potential mechanistic connections between sphingolipid and plant PCD and defense: (i) bioactive LCBs and ceramides function as signaling molecules in the activation of defense-related PCD; (ii) sphingolipids as organizing/signaling elements regulate polarized/targeted membrane trafficking involved in defense; and (iii) sphingolipids provide structural support for the formation of membrane microdomains where immunity proteins may assemble and function.

It is necessary to point out that despite the extensive genetic and biochemical evidence for the "death" connection, whether SPI-PCD is a more mechanistic equivalent of HR requires further investigation. In addition, while it is clear that SPI-PCD is exploited by necrotrophic fungal pathogens for pathogenesis, given that SPI-PCD (and HR) can be separable from resistance, whether SPI-PCD (and HR) plays a role in resistance to (hemi)biotrophic pathogens also remains to be determined. If $\mathrm{HR}$ is simply an unavoidable consequence of the escalated inter-organismal warfare in which antimicrobial chemicals reach a level that is lethal to both the enemy and self (Wang et al., 2008; Coll et al., 2011), then SPI-PCD may partly reflect the biochemical/biophysical nature of $\mathrm{HR}$ - that is, the perturbation or dysfunction of sphingolipid metabolism. On the other hand, research on immunity-related membrane trafficking and subcompartmentalization is currently at its early stage. Definitive genetic, biochemical, and cell biological evidence is awaited to establish the roles of sphingolipids in these processes. Thus, despite the prominent "death" connection, how sphingolipids and sphingolipid metabolism are involved in plant defense remains largely obscure.

Future work should be focused on the following questions to gain a better understanding of the physiological functions of sphingolipids in plant innate immunity. Is accumulation of bioactive sphingolipids the bona fide death signal for HR in ETI? If so, how does plant-pathogen recognition lead to accumulation of the bioactive sphingolipids and how is this step connected to SA signaling? Besides MPK6 as a potential direct protein target, what other proteins are directly regulated by the bioactive sphingolipids for activation of cell death? Do sphingolipids play a role in regulating defense protein secretion and targeting during plant defense? If so, what are the key sphingolipid species involved? If there truly exist defense-related microdomains in the plasma membrane and hostpathogen interfacial membranes such as the EHM, how do they form and what are the major sphingolipid and protein components of the microdomains? Apparently, a combinatory genetic, biochemical, and cell biological approach needs to be taken to address these challenging questions. For example, more targeted genetic screens are needed to identify additional components regulating both SPI-PCD and HR, and more powerful analytical technologies such as infrared spectrometry, high-performance liquid chromatography, and mass spectrometry are needed to systemically investigate the changes of the sphingolipidome during PTI and ETI in wild-type and various immune-compromised mutant plants. Finally, non-invasive cell biological tools are needed to determine the spatiotemporal dynamics of key sphingolipids in transport vesicles as well as in the plasma membrane during plant-pathogen interaction. In this regard, Kraut and colleagues recently made a fluorescent sphingolipid binding domain (SBD) peptide probe to track intracellular movements of sphingolipids in living neuronal cells. They demonstrated that fluorescently tagged SBD can be 


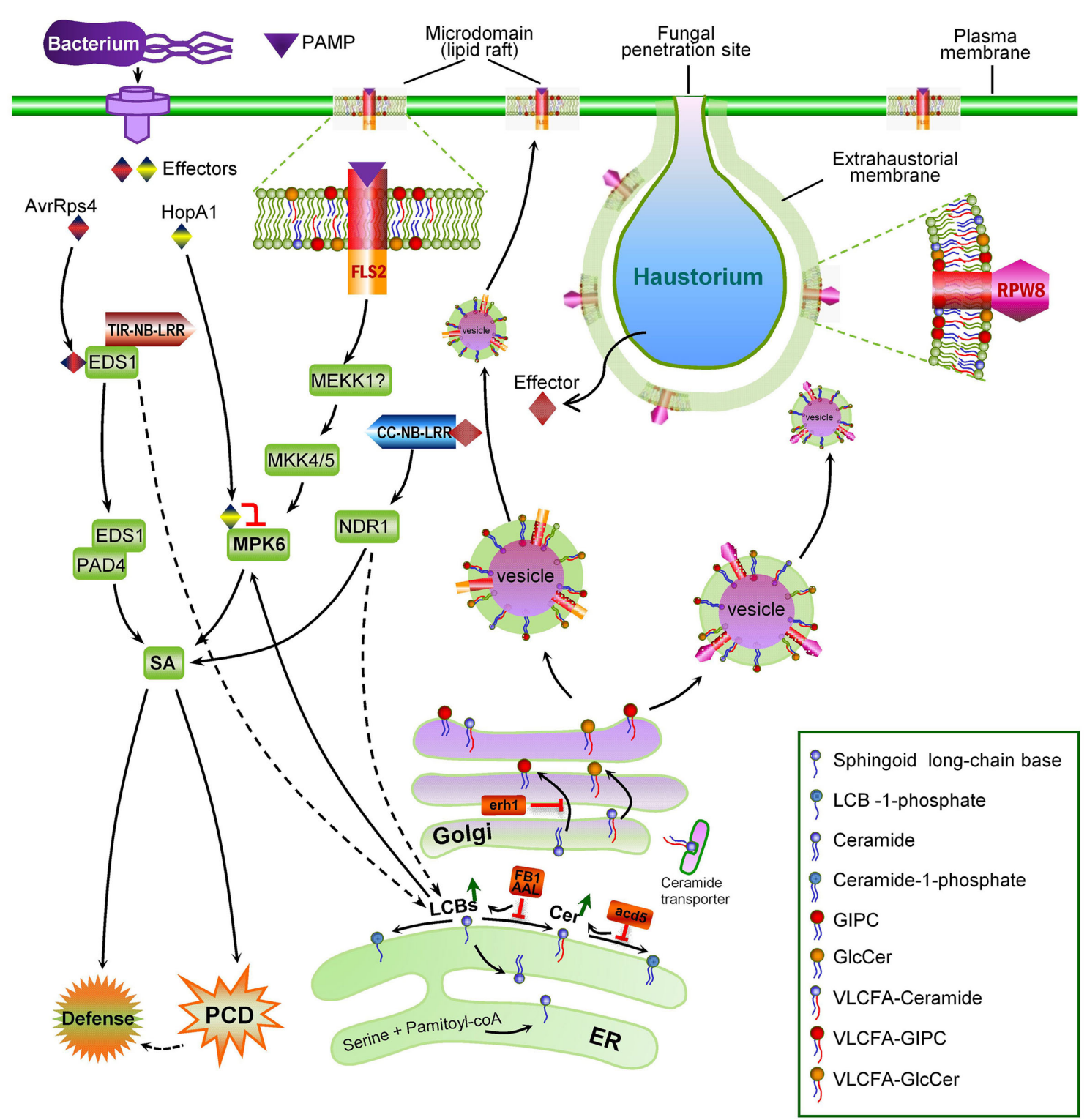

FIGURE 4 | A cartoon summarizing the major connections between sphingolipids and plant immunity. (i) PAMP-triggered immunity (PTI) involves a MAPK signaling module; MPK6 as a component of PTI is targeted by a pathogen effector HopA1 presumably for suppressing PTI. (ii) Effector-triggered immunity may involve accumulation of sphingoid long-chain bases (LCBs; t18:0 in particular) from de novo synthesis as an early signaling step upstream of SA. (iii) MPK6 is a potential direct protein target of LCBs; Upon activation by LCBs, MPK6 functions to promote SA-dependent HR and defense against (hemi)-biotrophic pathogens, thereby bridging up ETI and PTI. (iv) Some necrotrophic pathogens secrete toxin AAL or FB1 to inhibit (VLCFA-)ceramide synthesis and cause accumulation of LCBs, which in turn may activate MPK6, resulting in plant PCD for the benefit of the pathogens. (v) Ceramides are synthesized at the ER, and transferred to the Golgi apparatus where they are converted to inositol-phosphorylceramides (IPCS), and/or more complex

glycosphingolipids. Ceramide accumulation due to acd5 and erh1 mutations results in SA-dependent $P C D$, suggesting ceramides are essential signaling molecules for PCD. (vi) Glycosphingolipids (especially those containing VLCFAs) are sorted at the trans-Golgi into transport vesicles carrying relevant immune protein cargos (the FLS2 PAMP receptor and the RPW8 resistance protein as examples) to regulate specific targeting of cargos to specific cell membranes (the plasma membrane and the extrahaustorial membrane, respectively, in these two cases). (vi) Glycosphingolipids increase the molecular ordering of the cell membrane, forming microdomains (lipid rafts) that constitute lateral functional clusters in the cell membrane where plant immunity proteins may reside and function. used to investigate the dynamic nature of glycosphingolipid-rich, detergent-resistant microdomains (Hebbar et al., 2008; Steinert et al., 2008). Development and application of such SBD biosensors in plants will be very useful for examining the dynamic spatiotemporal distribution of sphingolipids in cell membranes and investigating how sphingolipids participate in membrane biogenesis, microdomain formation, and polarized protein trafficking in relation to plant defense. 


\section{ACKNOWLEDGMENTS}

The authors thank Wenming Wang for providing an image showing RPW8.2-YFP's localization and Yi Zhang for unpublished work discussed in this review. Research in the Xiao lab is supported by grants from National Science Foundation (grant number IOS-0842877 and IOS-0965353) to Shunyuan Xiao.

\section{REFERENCES}

Abbas, H. K., Duke, S. O., Paul, R. N., Riley, R. T., and Tanaka, T. (1995a). AAL-toxin, a potent natural herbicide which disrupts sphingolipid metabolism of plants. Pestic. Sci. 43, $181-187$.

Abbas, H. K., Tanaka, T., and Shier, W. T. (1995b). Biological activities of synthetic analogues of Alternaria alternata toxin (AAL-toxin) and fumonisin in plant and mammalian cell cultures. Phytochemistry 40, 1681-1689.

Abbas, H. K., Tanaka, T., Duke, S. O., Porter, J. K., Wray, E. M., Hodges, L., Sessions, A. E., Wang, E., Merrill, A. H. Jr., and Riley, R. T. (1994). Fumonisin- and AAL-toxin-induced disruption of sphingolipid metabolism with accumulation of free sphingoid bases. Plant Physiol. 106, 1085-1093.

Adie, B. A., Perez-Perez, J., PerezPerez, M. M., Godoy, M., SanchezSerrano, J. J., Schmelz, E. A., and Solano, R. (2007). ABA is an essential signal for plant resistance to pathogens affecting JA biosynthesis and the activation of defenses in Arabidopsis. Plant Cell 19, 1665-1681.

Aist, J. R. (1976). Papillae and related wound plugs of plantcells. Annu. Rev. Phytopathol. 14, 145-163.

Akaishi, J., Onda, M., Okamoto, J., Miyamoto, S., Nagahama, M., Ito, K., Yoshida, A., and Shimizu, K. (2007). Down-regulation of an inhibitor of cell growth, transmembrane protein 34 (TMEM34), in anaplastic thyroid cancer. J. Cancer Res. Clin. Oncol. 133, 213-218.

Akamatsu, H., Itoh, Y., Kodama, M., Otani, H., and Kohmoto, K. (1997). AAL-toxin-deficient mutants of Alternaria alternata tomato pathotype by restriction enzyme-mediated integration. Phytopathology 87, 967-972.

Alden, K. P., Dhondt-Cordelier, S., Mcdonald, K. L., Reape, T. J., Ng, C. K., Mccabe, P. F., and Leaver, C. J. (2011). Sphingolipid long chain base phosphates can regulate apoptotic-like programmed cell death in plants. Biochem. Biophys. Res. Commun. 410, 574-580.

Allen, J. A., Halverson-Tamboli, R. A., and Rasenick, M. M. (2007). Lipid raft microdomains and neurotransmitter signalling. Nat. Rev. Neurosci. 8, 128-140.
Asai, S., Mase, K., and Yoshioka, H. (2010). Role of nitric oxide and reactive oxide species in disease resistance to necrotrophic pathogens. Plant Signal. Behav. 5, 872-874.

Asai, T., Stone, J. M., Heard, J. E., Kovtun, Y., Yorgey, P., Sheen, J., and Ausubel, F. M. (2000). Fumonisin B1-induced cell death in Arabidopsis protoplasts requires jasmonate-, ethylene-, and salicylate-dependent signaling pathways. Plant Cell 12, 1823-1836.

Asai, T., Tena, G., Plotnikova, J., Willmann, M. R., Chiu, W. L., GomezGomez, L., Boller, T., Ausubel, F. M., and Sheen, J. (2002). MAP kinase signalling cascade in Arabidopsis innate immunity. Nature 415, 977-983.

Assaad, F. F., Qiu, J. L., Youngs, H., Ehrhardt, D., Zimmerli, L., Kalde, M., Wanner, G., Peck, S. C., Edwards, H., Ramonell, K., Somerville, C. R., and Thordal-Christensen, H. (2004). The PEN1 syntaxin defines a novel cellular compartment upon fungal attack and is required for the timely assembly of papillae. Mol. Biol. Cell 15, 5118-5129.

Aubert, A., Marion, J., Boulogne, C., Bourge, M., Abreu, S., Bellec, Y., Faure, J. D., and Satiat-Jeunemaitre, B. (2011). Sphingolipids involvement in plant endomembrane differentiation: the BY2 case. Plant J. $65,958-971$.

Axtell, M. J., and Staskawicz, B. J. (2003). Initiation of RPS2-specified disease resistance in Arabidopsis is coupled to the AvrRpt2-directed elimination of RIN4. Cell 112, 369-377.

Bedia, C., Levade, T., and Codogno, P. (2011). Regulation of autophagy by sphingolipids. Anticancer Agents Med. Chem. 11, 844-853.

Bhat, R. A., Miklis, M., Schmelzer, E., Schulze-Lefert, P., and Panstruga, R. (2005). Recruitment and interaction dynamics of plant penetration resistance components in a plasma membrane microdomain. Proc. Natl. Acad. Sci. U.S.A. 102, 3135-3140.

Bi, F. C., Zhang, Q. F., Liu, Z., Fang, C., Li, J., Su, J. B., Greenberg, J. T., Wang, H. B., and Yao, N. (2011). A conserved cysteine motif is critical for rice ceramide kinase activity and function. PLOS ONE 6, e18079. doi:10.1371/journal.pone.0018079

Bohlenius, H., Morch, S. M., Godfrey, D., Nielsen, M. E., and
Thordal-Christensen, H. (2010). The multivesicular body-localized GTPase ARFAlb/1c is important for callose deposition and ROR2 syntaxin-dependent preinvasive basal defense in barley. Plant Cell 22, 3831-3844.

Borner, G. H., Sherrier, D. J., Weimar, T., Michaelson, L. V., Hawkins, N. D., Macaskill, A., Napier, J. A., Beale, M. H., Lilley, K. S., and Dupree, P. (2005). Analysis of detergentresistant membranes in Arabidopsis. Evidence for plasma membrane lipid rafts. Plant Physiol. 137, 104-116.

Brandwagt, B. F., Kneppers, T. J., Nijkamp, H. J., and Hille, J. (2002). Overexpression of the tomato Asc1 gene mediates high insensitivity to AAL toxins and fumonisin $\mathrm{B} 1$ in tomato hairy roots and confers resistance to Alternaria alternata $\mathrm{f}$. sp. lycopersici in Nicotiana umbratica plants. Mol. Plant Microbe Interact. $15,35-42$.

Brandwagt, B. F., Mesbah, L. A., Takken, F. L., Laurent, P. L., Kneppers, T. J., Hille, J., and Nijkamp, H. J. (2000). A longevity assurance gene homolog of tomato mediates resistance to Alternaria alternata f. sp. lycopersici toxins and fumonisin B1. Proc. Natl. Acad. Sci. U.S.A. 97, 4961-4966.

Breslow, D. K., Collins, S. R., Bodenmiller, B., Aebersold, R., Simons, K., Shevchenko, A., Ejsing, C. S., and Weissman, J. S. (2010). Orm family proteins mediate sphingolipid homeostasis. Nature 463, 1048-1053.

Breslow, D. K., and Weissman, J. S. (2010). Membranes in balance: mechanisms of sphingolipid homeostasis. Mol. Cell 40, 267-279.

Brodersen, P., Petersen, M., Pike, H. M., Olszak, B., Skov, S., Odum, N., Jorgensen, L. B., Brown, R. E., and Mundy, J. (2002). Knockout of Arabidopsis accelerated-celldeath11 encoding a sphingosine transfer protein causes activation of programmed cell death and defense. Genes Dev. 16, 490-502.

Canonne, J., Marino, D., Jauneau, A., Pouzet, C., Briere, C., Roby, D., and Rivas, S. (2011). The Xanthomonas type III effector XopD targets the Arabidopsis transcription factor MYB30 to suppress plant defense. Plant Cell 23, 3498-3511.

Cantrel, C., Vazquez, T., Puyaubert, J., Reze, N., Lesch, M., Kaiser, W. M., Dutilleul, C., Guillas, I.,
Zachowski, A., and Baudouin, E. (2011). Nitric oxide participates in cold-responsive phosphosphingolipid formation and gene expression in Arabidopsis thaliana. New Phytol. 189, 415-427.

Carmona-Salazar, L., El Hafidi, M., Enriquez-Arredondo, C., VazquezVazquez, C., Gonzalez De La Vara, L. E., and Gavilanes-Ruiz, M. (2011). Isolation of detergent-resistant membranes from plant photosynthetic and non-photosynthetic tissues. Anal. Biochem. 417 220-227.

Chen, H., and Xiong, L. (2010). myo-Inositol-1-phosphate synthase is required for polar auxin transport and organ development. J. Biol. Chem. 285, 24238-24247.

Chen, M., Cahoon, E. B., SaucedoGarcía, M., Plasencia, J., and Gavilanes-Ruíz, M. (2010). "Plant sphingolipids: structure, synthesis, and function," in Advances in Photosynthesis and Respiration, eds $\mathrm{H}$. Wada and N. Murata (New York: Springer), 77-116.

Chen, M., Han, G., Dietrich, C. R., Dunn, T. M., and Cahoon, E. B. (2006). The essential nature of sphingolipids in plants as revealed by the functional identification and characterization of the Arabidopsis LCB1 subunit of serine palmitoyltransferase. Plant Cell 18 3576-3593.

Chen, M., Markham, J. E., Dietrich, C. R., Jaworski, J. G., and Cahoon, E. B. (2008). Sphingolipid longchain base hydroxylation is important for growth and regulation of sphingolipid content and composition in Arabidopsis. Plant Cell 20, 1862-1878.

Chisholm, S. T., Coaker, G., Day, B., and Staskawicz, B. J. (2006). Hostmicrobe interactions: shaping the evolution of the plant immune response. Cell 124, 803-814.

Clough, S. J., Fengler, K. A., Yu, I. C., Lippok, B., Smith, R. K. Jr., and Bent, A. F. (2000). The Arabidopsis dnd 1 "defense, no death" gene encodes a mutated cyclic nucleotide-gated ion channel. Proc. Natl. Acad. Sci. U.S.A. 97, 9323-9328.

Clouse, S. D., Martensen, A. N., and Gilchrist, D. G. (1985). Rapid purification of host-specific pathotoxins from Alternaria alternata f. sp. lycopersici by solid-phase adsorption on octadecylsilane. J. Chromatogr. 350, 255-263. 
Coll, N. S., Epple, P., and Dangl, J. L. (2011). Programmed cell death in the plant immune system. Cell Death Differ. 18, 1247-1256.

Coll, N. S., Vercammen, D., Smidler, A., Clover, C., Van Breusegem, F., Dangl, J. L., and Epple, P. (2010). Arabidopsis type I metacaspases control cell death. Science 330, 1393-1397.

Collins, N. C., Thordal-Christensen, H., Lipka, V., Bau, S., Kombrink, E., Qiu, J. L., Huckelhoven, R., Stein, M., Freialdenhoven, A., Somerville, S. C., and Schulze-Lefert, P. (2003). SNARE-protein-mediated disease resistance at the plant cell wall. Nature 425, 973-977.

Coursol, S., Fan, L. M., Le Stunff, H., Spiegel, S., Gilroy, S., and Assmann, S. M. (2003). Sphingolipid signalling in Arabidopsis guard cells involves heterotrimeric G proteins. Nature 423, 651-654.

Coursol, S., Le Stunff, H., Lynch, D. V., Gilroy, S., Assmann, S. M., and Spiegel, S. (2005). Arabidopsis sphingosine kinase and the effects of phytosphingosine-1-phosphate on stomatal aperture. Plant Physiol. 137, 724-737.

Cuvillier, O., Pirianov, G., Kleuser, B., Vanek, P. G., Coso, O. A., Gutkind, S., and Spiegel, S. (1996). Suppression of ceramide-mediated programmed cell death by sphingosine1-phosphate. Nature 381, 800-803.

D’Angelo, G., Polishchuk, E., Di Tullio, G., Santoro, M., Di Campli, A., Godi, A., West, G., Bielawski, J., Chuang, C. C., Van Der Spoel, A. C., Platt, F. M., Hannun, Y. A., Polishchuk, R., Mattjus, P., and De Matteis, M. A. (2007). Glycosphingolipid synthesis requires FAPP2 transfer of glucosylceramide. Nature 449, 62-67.

Denny, P. W., Shams-Eldin, H., Price, H. P., Smith, D. F., and Schwarz, R. T. (2006). The protozoan inositol phosphorylceramide synthase: a novel drug target that defines a new class of sphingolipid synthase. J. Biol. Chem. 281, 28200-28209.

Desikan, R., Hancock, J. T., Ichimura, K., Shinozaki, K., and Neill, S. J. (2001). Harpin induces activation of the Arabidopsis mitogen-activated protein kinases AtMPK4 and AtMPK6. Plant Physiol. 126, 1579-1587.

Desjardins, A. E., and Plattner, R. D. (2000). Fumonisin B(1)nonproducing strains of Fusarium verticillioides cause maize (Zea mays) ear infection and ear rot. J. Agric. Food Chem. 48, 5773-5780.

Desjardins, A. E., Plattner, R. D., Nelsen, T. C., and Leslie, J. F. (1995). Genetic analysis of fumonisin production and virulence of Gibberella fujikuroi mating population A (Fusarium moniliforme) on maize (Zea mays) seedlings. Appl. Environ. Microbiol. 61, 79-86.

Dietrich, C. R., Han, G., Chen, M., Berg, R. H., Dunn, T. M., and Cahoon, E. B. (2008). Loss-of-function mutations and inducible RNAi suppression of Arabidopsis LCB2 genes reveal the critical role of sphingolipids in gametophytic and sporophytic cell viability. Plant J. 54, 284-298.

D’Mello, N. P., Childress, A. M., Franklin, D. S., Kale, S. P., Pinswasdi, C., and Jazwinski, S. M (1994). Cloning and characterization of LAG1, a longevity-assurance gene in yeast. J. Biol. Chem. 269, 15451-15459.

Donahue, J. L., Alford, S. R., Torabinejad, J., Kerwin, R. E., Nourbakhsh, A., Ray, W. K., Hernick, M., Huang, X., Lyons, B. M., Hein, P. P., and Gillaspy, G. E. (2010). The Arabidopsis thaliana Myo-inositol 1-phosphate synthase 1 gene is required for Myo-inositol synthesis and suppression of cell death. Plant Cell 22, 888-903.

Dunn, T. M., Lynch, D. V., Michaelson, L. V., and Napier, J. A. (2004). A post-genomic approach to understanding sphingolipid metabolism in Arabidopsis thaliana. Ann. Bot. 93, 483-497.

Dykstra, M., Cherukuri, A., Sohn, H. W., Tzeng, S. J., and Pierce, S. K. (2003). Location is everything: lipid rafts and immune cell signaling. Annu. Rev. Immunol. 21, 457-481.

El Oirdi, M., and Bouarab, K. (2007). Plant signalling components EDS1 and SGT1 enhance disease caused by the necrotrophic pathogen Botrytis cinerea. New Phytol. 175, 131-139.

Fessler, M. B., and Parks, J. S. (2011). Intracellular lipid flux and membrane microdomains as organizing principles in inflammatory cell signaling. J. Immunol. 187, 1529-1535.

Friesen, T. L., Faris, J. D., Solomon, P. S., and Oliver, R. P. (2008). Host-specific toxins: effectors of necrotrophic pathogenicity. Cell. Microbiol. 10, 1421-1428.

Futerman, A. H. (2007). Cell biology: taxi service for lipids. Nature 449, 35-37.

Gan, Y., Zhang, L., Zhang, Z., Dong, S., Li, J., Wang, Y., and Zheng, X. (2009). The LCB2 subunit of the sphingolip biosynthesis enzyme serine palmitoyltransferase can function as an attenuator of the hypersensitive response and Baxinduced cell death. New Phytol. 181, 127-146.
Gault, C. R., Obeid, L. M., and Hannun, Y. A. (2010). An overview of sphingolipid metabolism: from synthesis to breakdown. Adv. Exp. Med. Biol. 688, 1-23.

Gilchrist, D., Wang, H., Dickman, M., Jones, C., and Winter, C. (1995a). Fumonisin and AAL-toxins - detection in food and induction of apoptosis in plant and animal-cells. Abstr. Pap. Am. Chem. Soc. 209, 112-AGFD.

Gilchrist, D. G., Wang, H., and Bostock, R. M. (1995b). Sphingosine-related mycotoxins in plant and animal diseases. Can. J. Bot. 73, S459-S467.

Gilchrist, D. G. (1997). Mycotoxins reveal connections between plants and animals in apoptosis and ceramide signaling. Cell Death Differ. 4, 689-698.

Gilchrist, D. G., and Grogan, R. G. (1976). Production and nature of a host-specific toxin from Alternaria alternata f. sp. lycopersici. Phytopathology 66, 165-171.

Glazebrook, J. (2005). Contrasting mechanisms of defense against biotrophic and necrotrophic pathogens. Annu. Rev. Phytopathol. 43, 205-227.

Glenn, A. E., Zitomer, N. C., Zimeri, A. M., Williams, L. D., Riley, R T., and Proctor, R. H. (2008). Transformation-mediated complementation of a FUM gene cluster deletion in Fusarium verticillioides restores both fumonisin production and pathogenicity on maize seedlings. Mol. Plant Microbe Interact. 21, 87-97.

Gomez-Munoz, A. (2004). Ceramide-1phosphate: a novel regulator of cell activation. FEBS Lett. 562, 5-10.

Gomez-Munoz, A. (2006). Ceramide 1-phosphate/ceramide, a switch between life and death. Biochim. Biophys. Acta 1758, 2049-2056.

Govrin, E. M., and Levine, A. (2000). The hypersensitive response facilitates plant infection by the necrotrophic pathogen Botrytis cinerea. Curr. Biol. 10, 751-757.

Granado, M. H., Gangoiti, P., Ouro, A., Arana, L., and Gomez-Munoz, A. (2009). Ceramide 1-phosphate inhibits serine palmitoyltransferase and blocks apoptosis in alveolar macrophages. Biochim. Biophys. Acta 1791, 263-272.

Grant, M. R., and Jones, J. D. (2009). Hormone (dis)harmony moulds plant health and disease. Science 324, 750-752.

Greenberg, J. T., Silverman, F. P., and Liang, H. (2000). Uncoupling salicylic acid-dependent cell death and defense-related responses from disease resistance in the Arabidopsis mutant acd5. Genetics 156, 341-350.

Grenier, B., and Oswald, I. P. (2011). Mycotoxin co-contamination of food and feed: meta-analysis of publications describing toxicological interactions. World Mycotoxin J. 4, 285-313.

Guillas, I., Jiang, J. C., Vionnet, C., Roubaty, C., Uldry, D., Chuard, R., Wang, J., Jazwinski, S. M., and Conzelmann, A. (2003). Human homologues of LAG1 reconstitute Acyl-CoA-dependent ceramide synthesis in yeast. J. Biol. Chem. 278, 37083-37091.

Guillas, I., Kirchman, P. A., Chuard, R., Pfefferli, M., Jiang, J. C., Jazwinski, S. M., and Conzelmann, A. (2001). C26-CoA-dependent ceramide synthesis of Saccharomyces cerevisiae is operated by Laglp and Laclp. EMBO J. 20, 2655-2665.

Guo, L., Mishra, G., Taylor, K., and Wang, X. (2011). Phosphatidic acid binds and stimulates Arabidopsis sphingosine kinases. J. Biol. Chem. 286, 13336-13345.

Han, S., Lone, M. A., Schneiter, R., and Chang, A. (2010). Orm1 and Orm2 are conserved endoplasmic reticulum membrane proteins regulating lipid homeostasis and protein quality control. Proc. Natl. Acad. Sci. U.S.A. 107, 5851-5856

Hanada, K. (2003). Serine palmitoyltransferase, a key enzyme of sphingolipid metabolism. Biochim. Biophys. Acta 1632, 16-30.

Hanada, K., Kumagai, K., Yasuda, S., Miura, Y., Kawano, M., Fukasawa, M., and Nishijima, M. (2003). Molecular machinery for non-vesicular trafficking of ceramide. Nature 426, 803-809.

Hannun, Y. A. (1996). Functions of ceramide in coordinating cellular responses to stress. Science 274, 1855-1859.

Hannun, Y. A., Loomis, C. R., Merrill, A. H. Jr., and Bell, R. M. (1986). Sphingosine inhibition of protein kinase $\mathrm{C}$ activity and of phorbol dibutyrate binding in vitro and in human platelets. J. Biol. Chem. 261, 12604-12609.

Hannun, Y. A., and Obeid, L. M. (2008). Principles of bioactive lipid signalling: lessons from sphingolipids. Nat. Rev. Mol. Cell Biol. 9, 139-150.

Hannun, Y. A., and Obeid, L. M. (2011). Many ceramides. J. Biol. Chem. 286, 27855-27862.

Hardham, A. R., Jones, D. A., and Takemoto, D. (2007). Cytoskeleton and 
cell wall function in penetration resistance. Curr. Opin. Plant Biol. 10, 342-348.

Hartlova, A., Cerveny, L., Hubalek, M., Krocova, Z., and Stulik, J. (2010). Membrane rafts: a potential gateway for bacterial entry into host cells. Microbiol. Immunol. 54, 237-245.

Heath, M. C. (2000). Hypersensitive response-related death. Plant $\mathrm{Mol}$. Biol. 44, 321-334.

Hebbar, S., Lee, E., Manna, M., Steinert, S., Kumar, G. S., Wenk, M., Wohland, T., and Kraut, R. (2008). A fluorescent sphingolipid binding domain peptide probe interacts with sphingolipids and cholesteroldependent raft domains. J. Lipid Res. 49, 1077-1089.

Hinkovska-Galcheva, V., and Shayman, J. A. (2010). Ceramide-1-phosphate in phagocytosis and calcium homeostasis. Adv. Exp. Med. Biol. 688, 131-140.

Israel, H. W., Wilson, R. G., Aist, J. R., and Kunoh, H. (1980). Cellwall appositions and plant-disease resistance - acoustic microscopy of papillae that block fungal ingress. Proc. Natl. Acad. Sci. U.S.A. 77, 2046-2049.

Jarsch, I. K., and Ott, T. (2011). Perspectives on remorin proteins, membrane rafts, and their role during plant-microbe interactions. Mol. Plant Microbe Interact. 24, 7-12.

Jin, R., Yuan, W. X., Xu, H. G., Ren, W., Zhuang, L. L., and Zhou, G. P. (2011). Characterization of a novel isoform of the human ORMDL3 gene. Cell Tissue Res. 346, 203-208.

Jones, J. D., and Dangl, J. L. (2006). The plant immune system. Nature 444, 323-329.

Jurkowski, G. I., Smith, R. K. Jr., Yu, I. C., Ham, J. H., Sharma, S. B., Klessig, D. F., Fengler, K. A., and Bent, A. F. (2004). Arabidopsis DND2, a second cyclic nucleotide-gated ion channel gene for which mutation causes the "defense, no death" phenotype. Mol. Plant Microbe Interact. 17, 511-520.

Kale, S. D., Gu, B., Capelluto, D. G., Dou, D., Feldman, E., Rumore, A., Arredondo, F. D., Hanlon, R., Fudal, I., Rouxel, T., Lawrence, C. B., Shan, W., and Tyler, B. M. (2010). External lipid PI3P mediates entry of eukaryotic pathogen effectors into plant and animal host cells. Cell 142, 284-295.

Keinath, N. F., Kierszniowska, S., Lorek, J., Bourdais, G., Kessler, S. A., Shimosato-Asano, H., Grossniklaus, U., Schulze, W. X., Robatzek, S., and Panstruga, R. (2010). PAMP (pathogen-associated molecular pattern)-induced changes in plasma membrane compartmentalization reveal novel components of plant immunity. J. Biol. Chem. 285, 39140-39149.

Kiedrowski, S., Kawalleck, P., Hahlbrock, K., Somssich, I. E., and Dangl, J. L. (1992). Rapid activation of a novel plant defense gene is strictly dependent on the Arabidopsis RPM1 disease resistance locus. EMBO J. 11, 4677-4684.

Kierszniowska, S., Seiwert, B., and Schulze, W. X. (2009). Definition of Arabidopsis sterol-rich membrane microdomains by differential treatment with methyl-betacyclodextrin and quantitative proteomics. Mol. Cell Proteomics 8, 612-623.

Kitatani, K., Idkowiak-Baldys, J., and Hannun, Y. A. (2008). The sphingolipid salvage pathway in ceramide metabolism and signaling. Cell. Signal. 20, 1010-1018.

Klemm, R. W., Ejsing, C. S., Surma, M. A., Kaiser, H. J., Gerl, M. J., Sampaio, J. L., De Robillard, Q., Ferguson, C., Proszynski, T. J., Shevchenko, A., and Simons, K. (2009). Segregation of sphingolipids and sterols during formation of secretory vesicles at the trans-Golgi network. J. Cell Biol. 185, 601-612.

Koga, J., Yamauchi, T., Shimura, M., Ogawa, N., Oshima, K., Umemura, K., Kikuchi, M., and Ogasawara, N. (1998). Cerebrosides A and C, sphingolipid elicitors of hypersensitive cell death and phytoalexin accumulation in rice plants. J. Biol. Chem. 273, 31985-31991.

Koh, S., Andre, A., Edwards, H., Ehrhardt, D., and Somerville, S. (2005). Arabidopsis thaliana subcellular responses to compatible Erysiphe cichoracearum infections. Plant J. 44, 516-529.

Kuroyanagi, M., Yamada, K., Hatsugai, N., Kondo, M., Nishimura, M., and Hara-Nishimura, I. (2005). Vacuolar processing enzyme is essential for mycotoxin-induced cell death in Arabidopsis thaliana. J. Biol. Chem. 280, 32914-32920.

Kurusu, T., Hamada, H., Sugiyama, Y., Yagala, T., Kadota, Y., Furuichi, T., Hayashi, T., Umemura, K., Komatsu, S., Miyao, A., Hirochika, H., and Kuchitsu, K. (2011). Negative feedback regulation of microbe-associated molecular pattern-induced cytosolic $\mathrm{Ca}^{2+}$ transients by protein phosphorylation. J. Plant Res. 124, 415-424.

Kwon, C., Neu, C., Pajonk, S., Yun, H. S., Lipka, U., Humphry, M., Bau,
S., Straus, M., Kwaaitaal, M., Rampelt, H., El Kasmi, F., Jurgens, G., Parker, J., Panstruga, R., Lipka, V., and Schulze-Lefert, P. (2008). Cooption of a default secretory pathway for plant immune responses. Nature 451, 835-840.

Lachaud, C., Da Silva, D., Amelot, N., Beziat, C., Briere, C., Cotelle, V., Graziana, A., Grat, S., Mazars, C., and Thuleau, P. (2011). Dihydrosphingosine-induced programmed cell death in tobacco BY-2 cells is independent of $\mathrm{HO}$ production. Mol. Plant 4, 310-318.

Lachaud, C., Da Silva, D., Cotelle, V., Thuleau, P., Xiong, T. C., Jauneau, A., Briere, C., Graziana, A., Bellec, Y., Faure, J. D., Ranjeva, R., and Mazars, C. (2010). Nuclear calcium controls the apoptotic-like cell death induced by d-erythro-sphinganine in tobacco cells. Cell Calcium 47, 92-100.

Lawrence, C. B., Mitchell, T. K. Craven, K. D., Cho, Y., Cramer, R. A., and Kim, K. H. (2008). At death's door: Alternaria pathogenicity mechanisms. Plant Pathol. J. 24, 101-111.

Lherminier, J., Elmayan, T., Fromentin, J., Elaraqui, K. T., Vesa, S., Morel, J., Verrier, J. L., Cailleteau, B., Blein, J. P., and Simon-Plas, F. (2009). NADPH oxidase-mediated reactive oxygen species production: subcellular localization and reassessment of its role in plant defense. Mol. Plant Microbe Interact. 22, 868-881.

Li, J., Brader, G., and Palva, E. T. (2008). Kunitz trypsin inhibitor: an antagonist of cell death triggered by phytopathogens and fumonisin b1 in Arabidopsis. Mol. Plant 1, 482-495.

Liang, H., Yao, N., Song, J. T., Luo, S., Lu, H., and Greenberg, J. T. (2003). Ceramides modulate programmed cell death in plants. Genes Dev. 17, 2636-2641.

Lieberherr, D., Thao, N. P., Nakashima, A., Umemura, K., Kawasaki, T., and Shimamoto, K. (2005). A sphingolipid elicitor-inducible mitogenactivated protein kinase is regulated by the small GTPase OsRac1 and heterotrimeric G-protein in rice 1[w]. Plant Physiol. 138, 1644-1652.

Lingwood, D., and Simons, K. (2010). Lipid rafts as a membraneorganizing principle. Science 327, 46-50.

Lorang, J., Cuesta-Marcos, A., Hayes, P. M., and Wolpert, T. J. (2010). Identification and mapping of adult-onset sensitivity to victorin in barley. Mol. Breed. 26, 545-550.

Lorrain, S., Vailleau, F., Balague, C., and Roby, D. (2003). Lesion mimic mutants: keys for deciphering cell death and defense pathways in plants? Trends Plant Sci. 8, 263-271. Luo, Y., Qin, G., Zhang, J., Liang, Y., Song, Y., Zhao, M., Tsuge, T., Aoyama, T., Liu, J., Gu, H., and Qu, L. J. (2011). D-myoinositol-3-phosphate affects phosphatidylinositol-mediated endomembrane function in Arabidopsis and is essential for auxin-regulated embryogenesis. Plant Cell 23, 1352-1372.

Mackey, D., Belkhadir, Y., Alonso, J. M., Ecker, J. R., and Dangl, J. L. (2003). Arabidopsis RIN4 is a target of the type III virulence effector AvrRpt2 and modulates RPS2-mediated resistance. Cell 112, 379-389.

Malinina, L., Malakhova, M. L., Teplov, A., Brown, R. E., and Patel, D. J. (2004). Structural basis for glycosphingolipid transfer specificity. Nature 430, 1048-1053.

Malinovsky, F. G., Brodersen, P., Fiil, B. K., Mckinney, L. V., Thorgrimsen, S., Beck, M., Nielsen, H. B., Pietra, S., Zipfel, C., Robatzek, S., Petersen, M., Hofius, D., and Mundy, J. (2010). Lazarus1, a DUF300 protein, contributes to programmed cell death associated with Arabidopsis acd11 and the hypersensitive response. PLOS ONE 5, e12586. doi:10.1371/journal.pone.0012586

Mao, C., and Obeid, L. M. (2008) Ceramidases: regulators of cellular responses mediated by ceramide, sphingosine, and sphingosine-1phosphate. Biochim. Biophys. Acto 1781, 424-434.

Marasas, W. F. (2001). Discovery and occurrence of the fumonisins: a historical perspective. Environ. Health Perspect. 109(Suppl. 2), 239-243.

Marathe, R., and Dinesh-Kumar, S. P. (2003). Plant defense: one post, multiple guards?! Mol. Cell 11, 284-286.

Markham, J. E., and Jaworski, J. G. (2007). Rapid measurement of sphingolipids from Arabidopsis thaliana by reversed-phase highperformance liquid chromatography coupled to electrospray ionization tandem mass spectrometry. Rapid Commun. Mass Spectrom. 21, 1304-1314.

Markham, J. E., Li, J., Cahoon, E. B., and Jaworski, J. G. (2006). Separation and identification of major plant sphingolipid classes from leaves. $J$. Biol. Chem. 281, 22684-22694.

Markham, J. E., Molino, D., Gissot, L., Bellec, Y., Hematy, K., Marion, J., Belcram, K., Palauqui, J. C., Satiat-Jeunemaitre, B., and Faure, J. D. (2011). Sphingolipids containing very-long-chain fatty acids define a 
secretory pathway for specific polar plasma membrane protein targeting in Arabidopsis. Plant Cell 23, 2362-2378.

Mayer, A. M., Staples, R. C., and Gil-Ad, N. L. (2001). Mechanisms of survival of necrotrophic fungal plant pathogens in hosts expressing the hypersensitive response. Phytochemistry 58, 33-41.

Meng, P. H., Raynaud, C., Tcherkez, G., Blanchet, S., Massoud, K., Domenichini, S., Henry, Y., SoubigouTaconnat, L., Lelarge-Trouverie, C., Saindrenan, P., Renou, J. P., and Bergounioux, C. (2009). Crosstalks between myo-inositol metabolism, programmed cell death and basal immunity in Arabidopsis. PLoS ONE 4, e7364. doi:10.1371/journal.pone. 0007364

Menke, F. L., Van Pelt, J. A., Pieterse, C. M., and Klessig, D. F. (2004). Silencing of the mitogen-activated protein kinase MPK6 compromises disease resistance in Arabidopsis. Plant Cell $16,897-907$

Merrill, A. H. Jr. (2011). Sphingolipid and glycosphingolipid metabolic pathways in the era of sphingolipidomics. Chem. Rev. 111, 6387-6422.

Merrill, A. H. Jr., Stokes, T. H., Momin, A., Park, H., Portz, B. J., Kelly, S., Wang, E., Sullards, M. C., and Wang, M. D. (2009). Sphingolipidomics: a valuable tool for understanding the roles of sphingolipids in biology and disease. J. Lipid Res. 50(Suppl.), S97-S102.

Merrill, A. H. Jr., Wang, M. D., Park, M., and Sullards, M. C. (2007). (Glyco)sphingolipidology: an amazing challenge and opportunity for systems biology. Trends Biochem. Sci. 32, 457-468.

Merrill, A. H., Wang, E., Gilchrist, D. G., and Riley, R. T. (1993). Fumonisins and other inhibitors of de-novo sphingolipid biosynthesis. Adv. Lipid Res. 26, 215-234.

Michaelson, L. V., Zauner, S., Markham, J. E., Haslam, R. P., Desikan, R., Mugford, S., Albrecht, S., Warnecke, D. Sperling, P., Heinz, E., and Napier, J. A. (2009). Functional characterization of a higher plant sphingolipid Delta4-desaturase: defining the role of sphingosine and sphingosine1-phosphate in Arabidopsis. Plant Physiol. 149, 487-498.

Mina, J. G., Okada, Y., WansadhipathiKannangara, N. K., Pratt, S., ShamsEldin, H., Schwarz, R. T., Steel, P. G., Fawcett, T., and Denny, P. W. (2010). Functional analyses of differentially expressed isoforms of the Arabidopsis inositol phosphorylceramide synthase. Plant Mol. Biol. 73, 399-407.

Mirocha, C. J., Gilchrist, D. G., Shier, W. T., Abbas, H. K., Wen, Y., and Vesonder, R. F. (1992). AAL toxins, fumonisins (biology and chemistry) and host-specificity concepts. Mycopathologia 117, 47-56.

Moeder, W., and Yoshioka, K. (2008). Lesion mimic mutants: a classical, yet still fundamental approach to study programmed cell death. Plant Signal. Behav. 3, 764-767.

Morris, R. J., Jen, A., and Warley, A. (2011). Isolation of nano-meso scale detergent resistant membrane that has properties expected of lipid 'rafts'. J. Neurochem. 116, 671-677.

Mullen, T. D., Jenkins, R. W., Clarke, C. J., Bielawski, J., Hannun, Y. A., and Obeid, L. M. (2011a). Ceramide synthase-dependent ceramide generation and programmed cell death: involvement of salvage pathway in regulating postmitochondrial events. J. Biol. Chem. 286, 15929-15942.

Mullen, T. D., Spassieva, S., Jenkins, R. W., Kitatani, K., Bielawski, J., Hannun, Y. A., and Obeid, L. M. (2011b). Selective knockdown of ceramide synthases reveals complex interregulation of sphingolipid metabolism. J. Lipid Res. 52, 68-77.

Mur, L. A., Kenton, P., Lloyd, A. J. Ougham, H., and Prats, E. (2008). The hypersensitive response; the centenary is upon us but how much do we know? J. Exp. Bot. 59, 501-520.

Nagano, M., Ihara-Ohori, Y., Imai, H., Inada, N., Fujimoto, M., Tsutsumi, N., Uchimiya, H., and KawaiYamada, M. (2009). Functional association of cell death suppressor, Arabidopsis Bax inhibitor-1, with fatty acid 2-hydroxylation through cytochrome b. Plant J. 58, 122-134.

Nagiec, M. M., Nagiec, E. E., Baltisberger, J. A., Wells, G. B., Lester, R. L., and Dickson, R. C. (1997). Sphingolipid synthesis as a target for antifungal drugs. Complementation of the inositol phosphorylceramide synthase defect in a mutant strain of Saccharomyces cerevisiae by the AUR1 gene. J. Biol. Chem. 272, 9809-9817.

Ng, C. K., Carr, K., Mcainsh, M. R., Powell, B., and Hetherington, A. M. (2001). Drought-induced guard cell signal transduction involves sphingosine-1-phosphate. Nature 410, 596-599.

Nikolova-Karakashian, M. N., and Rozenova, K. A. (2010). Ceramide in stress response. Adv. Exp. Med. Biol. $688,86-108$.
Nishimura, M. T., Stein, M., Hou, B. H., Vogel, J. P., Edwards, H., and Somerville, S. C. (2003). Loss of a callose synthase results in salicylic acid-dependent disease resistance. Science 301, 969-972.

Norred, W. P., Plattner, R. D., Dombrink-Kurtzman, M. A., Meredith, F. I., and Riley, R. T. (1997). Mycotoxin-induced elevation of free sphingoid bases in precision-cut rat liver slices: specificity of the response and structure-activity relationships. Toxicol. Appl. Pharmacol. 147, 63-70.

Obeid, L. M., Linardic, C. M., Karolak, L. A., and Hannun, Y. A. (1993). Programmed cell death induced by ceramide. Science 259, 1769-1771.

Ohno, Y., Suto, S., Yamanaka, M., Mizutani, Y., Mitsutake, S., Igarashi, Y. Sassa, T., and Kihara, A. (2010). ELOVL1 production of $\mathrm{C} 24$ acylCoAs is linked to C24 sphingolipid synthesis. Proc. Natl. Acad. Sci. U.S.A. 107, 18439-18444.

Oliver, R. P., and Solomon, P. S. (2010) New developments in pathogenicity and virulence of necrotrophs. Curr. Opin. Plant Biol. 13 415-419.

Palma, K., Thorgrimsen, S., Malinovsky, F. G., Fiil, B. K., Nielsen, H. B., Brodersen, P., Hofius, D. Petersen, M., and Mundy, J. (2010). Autoimmunity in Arabidopsis acd 11 is mediated by epigenetic regulation of an immune receptor. PLoS Pathog. 6, el001137. doi:10.1371/journal.ppat.1001137

Parton, R. G., and Hancock, J. F. (2004). Lipid rafts and plasma membrane microorganization: insights from Ras. Trends Cell Biol. 14, 141-147.

Pata, M. O., Hannun, Y. A., and Ng, C. K. (2010). Plant sphingolipids: decoding the enigma of the Sphinx. New Phytol. 185, 611-630.

Pata, M. O., Wu, B. X., Bielawski, J., Xiong, T. C., Hannun, Y. A., and Ng, C. K. (2008). Molecular cloning and characterization of OsCDase, a ceramidase enzyme from rice. Plant J. 55, 1000-1009.

Peer, M., Stegmann, M., Mueller, M. J., and Waller, F. (2010). Pseudomonas syringae infection triggers de novo synthesis of phytosphingosine from sphinganine in Arabidopsis thaliana. FEBS Lett. 584, 4053-4056.

Petersen, N. H., Joensen, J., Mckinney, L. V., Brodersen, P., Petersen, M., Hofius, D., and Mundy, J. (2009). Identification of proteins interacting with Arabidopsis ACD11. J. Plant Physiol. 166, 661-666.
Petersen, N. H., Mckinney, L. V., Pike, H., Hofius, D., Zakaria, A., Brodersen, P., Petersen, M., Brown, R. E., and Mundy, J. (2008). Human GLTP and mutant forms of ACD11 suppress cell death in the Arabidopsis acd11 mutant. FEBS J. 275, 4378-4388.

Pewzner-Jung, Y., Park, H., Laviad, E. L., Silva, L. C., Lahiri, S., Stiban, J., Erez-Roman, R., Brugger, B., Sachsenheimer, T., Wieland, F., Prieto, M., Merrill, A. H. Jr., and Futerman, A. H. (2010). A critical role for ceramide synthase 2 in liver homeostasis: I. Alterations in lipid metabolic pathways. J. Biol. Chem. 285, 10902-10910.

Pinelli, E., Poux, N., Garren, L., Pipy, B., Castegnaro, M., Miller, D. J., and Pfohl-Leszkowicz, A. (1999). Activation of mitogen-activated protein kinase by fumonisin $\mathrm{B}(1)$ stimulates CPLA(2) phosphorylation, the arachidonic acid cascade and cAMP production. Carcinogenesis 20, 1683-1688.

Pitzschke, A., Schikora, A., and Hirt, H. (2009). MAPK cascade signalling networks in plant defence. Curr Opin. Plant Biol. 12, 421-426.

Pumplin, N., and Harrison, M. J. (2009). Live-cell imaging reveals periarbuscular membrane domains and organelle location in Medicago truncatula roots during arbuscular mycorrhizal symbiosis. Plant Physiol. 151, 809-819.

Quist, T. M., Sokolchik, I., Shi, H., Joly, R. J., Bressan, R. A., Maggio, A. Narsimhan, M., and Li, X. (2009). HOS3, an ELO-like gene, inhibits effects of ABA and implicates a S-1$\mathrm{P} /$ ceramide control system for abiotic stress responses in Arabidopsis thaliana. Mol. Plant 2, 138-151.

Racape, J., Belbahri, L., Engelhardt, S., Lacombe, B., Lee, J., Lochman, J., Marais, A., Nicole, M., Nurnberger, T., Parlange, F., Puverel, S., and Keller, H. (2005). $\mathrm{Ca}^{2+}$. dependent lipid binding and membrane integration of PopA, a harpinlike elicitor of the hypersensitive response in tobacco. Mol. Microbiol. $58,1406-1420$

Raffaele, S., Rivas, S., and Roby, D. (2006). An essential role for salicylic acid in AtMYB30-mediated control of the hypersensitive cell death program in Arabidopsis. FEBS Lett. 580, 3498-3504.

Raffaele, S., Vailleau, F., Leger, A., Joubes, J., Miersch, O., Huard, C., Blee, E., Mongrand, S., Domergue, F., and Roby, D. (2008). A MYB transcription factor regulates very-longchain fatty acid biosynthesis for 
activation of the hypersensitive cell death response in Arabidopsis. Plant Cell 20, 752-767.

Reape, T. J., Molony, E. M., and Mccabe, P. F. (2008). Programmed cell death in plants: distinguishing between different modes. J. Exp. Bot. 59, 435-444.

Reina-Pinto, J. J., Voisin, D., Kurdyukov, S., Faust, A., Haslam, R. P., Michaelson, L. V., Efremova, N., Franke, B., Schreiber, L., Napier, J. A., and Yephremov, A. (2009). Misexpression of FATTY ACID ELONGATION1 in the Arabidopsis epidermis induces cell death and suggests a critical role for phospholipase A2 in this process. Plant Cell 21, 1252-1272.

Riebeling, C., Allegood, J. C., Wang, E., Merrill, A. H. Jr., and Futerman, A. H. (2003). Two mammalian longevity assurance gene (LAG1) family members, trh1 and trh4, regulate dihydroceramide synthesis using different fatty acylCoA donors. J. Biol. Chem. 278, 43452-43459.

Riley, R. T., Wang, E., Schroeder, J. J., Smith, E. R., Plattner, R. D., Abbas, H., Yoo, H. S., and Merrill, A. H. Jr. (1996). Evidence for disruption of sphingolipid metabolism as a contributing factor in the toxicity and carcinogenicity of fumonisins. Nat. Toxins 4, 3-15.

Robatzek, S., Chinchilla, D., and Boller, T. (2006). Ligand-induced endocytosis of the pattern recognition receptor FLS2 in Arabidopsis. Genes Dev. 20, 537-542.

Roelants, F. M., Breslow, D. K., Muir, A., Weissman, J. S., and Thorner, J. (2011). Protein kinase Ypk1 phosphorylates regulatory proteins Orm1 and Orm2 to control sphingolipid homeostasis in Saccharomyces cerevisiae. Proc. Natl. Acad. Sci. U.S.A. 108, 19222-19227.

Roudier, F., Gissot, L., Beaudoin, F., Haslam, R., Michaelson, L., Marion, J., Molino, D., Lima, A., Bach, L., Morin, H., Tellier, F., Palauqui, J. C., Bellec, Y., Renne, C., Miquel, M., Dacosta, M., Vignard, J., Rochat, C., Markham, J. E., Moreau, P., Napier, J., and Faure, J. D. (2010). Very-longchain fatty acids are involved in polar auxin transport and developmental patterning in Arabidopsis. Plant Cell 22, 364-375.

Sanchez-Rangel, D., Sanchez-Nieto, S., and Plasencia, J. (2011). Fumonisin B1, a toxin produced by Fusarium verticillioides, modulates maize beta-1,3-glucanase activities involved in defense response. Planta. doi:10.1007/s00425-011-1555-0. [Epub ahead of print].
Sasaki, T. (1985). Glycolipid-binding proteins. Chem. Phys. Lipids 38, 63-77.

Saucedo-Garcia, M., Gonzalez-Solis, A., Rodriguez-Mejia, P., OliveraFlores, T. D., Vazquez-Santana, S., Cahoon, E. B., and Gavilanes-Ruiz, M. (2011a). Reactive oxygen species as transducers of sphinganinemediated cell death pathway. Plant Signal. Behav. 6.

Saucedo-Garcia, M., Guevara-Garcia, A., Gonzalez-Solis, A., Cruz-Garcia, F., Vazquez-Santana, S., Markham, J. E., Lozano-Rosas, M. G., Dietrich, C. R., Ramos-Vega, M., Cahoon, E. B., and Gavilanes-Ruiz, M. (2011b). MPK6, sphinganine and the LCB2a gene from serine palmitoyltransferase are required in the signaling pathway that mediates cell death induced by long chain bases in Arabidopsis. New Phytol. 191, 943-957.

Schmelz, E. M., Dombrink-Kurtzman, M. A., Roberts, P. C., Kozutsumi, Y., Kawasaki, T., and Merrill, A. H. Jr. (1998). Induction of apoptosis by fumonisin B1 in HT29 cells is mediated by the accumulation of endogenous free sphingoid bases. Toxicol. Appl. Pharmacol. 148, 252-260.

Schmelzer, E. (2002). Cell polarization, a crucial process in fungal defence. Trends Plant Sci. 7, 411-415.

Schorling, S., Vallee, B., Barz, W. P., Riezman, H., and Oesterhelt, D. (2001). Laglp and Laclp are essential for the Acyl-CoA-dependent ceramide synthase reaction in Saccharomyces cerevisiae. Mol. Biol. Cell 12, 3417-3427.

Shevchenko, A., and Simons, K. (2010). Lipidomics: coming to grips with lipid diversity. Nat. Rev. Mol. Cell Biol. 11, 593-598.

Shi, L., Bielawski, J., Mu, J., Dong, H., Teng, C., Zhang, J., Yang, X., Tomishige, N., Hanada, K., Hannun, Y. A., and Zuo, J. (2007). Involvement of sphingoid bases in mediating reactive oxygen intermediate production and programmed cell death in Arabidopsis. Cell Res. 17, 1030-1040.

Shier, W. T., Abbas, H. K., and Badria, F. A. (1995). Complete structures of the sphingosine analog mycotoxins fumonisin B-1 and AAL toxin TA - absolute-configuration of the side-chains. Tetrahedron Lett. 36, 1571-1574.

Shier, W. T., Abbas, H. K., and Mirocha, C. J. (1991). Toxicity of the mycotoxins fumonisins $\mathrm{B} 1$ and $\mathrm{B} 2$ and Alternaria alternata f. sp. lycopersici toxin (AAL) in cultured mammalian cells. Mycopathologia 116, 97-104.
Spassieva, S. D., Markham, J. E., and Hille, J. (2002). The plant disease resistance gene Asc-1 prevents disruption of sphingolipid metabolism during AAL-toxin-induced programmed cell death. Plant J. 32, 561-572.

Spiegel, S., Cuvillier, O., Edsall, L. C., Kohama, T., Menzeleev, R., Olah, Z., Olivera, A., Pirianov, G., Thomas, D. M., Tu, Z., Van Brocklyn, J. R., and Wang, F. (1998). Sphingosine1-phosphate in cell growth and cell death. Ann. N. Y. Acad. Sci. 845 11-18.

Spiegel, S., and Milstien, S. (2003). Sphingosine-1-phosphate: an enigmatic signalling lipid. Nat. Rev. Mol. Cell Biol. 4, 397-407.

Stancevic, B., and Kolesnick, R. (2010). Ceramide-rich platforms in transmembrane signaling. FEBS Lett. 584 1728-1740.

Stein, M., Dittgen, J., SanchezRodriguez, C., Hou, B. H., Molina, A., Schulze-Lefert, P., Lipka, V., and Somerville, S. (2006). Arabidopsis PEN3/PDR8, an ATP binding cassette transporter, contributes to nonhost resistance to inappropriate pathogens that enter by direct penetration. Plant Cell 18, 731-746.

Steinert, S., Lee, E., Tresset, G., Zhang, D., Hortsch, R., Wetzel, R., Hebbar, S., Sundram, J. R., Kesavapany, S., Boschke, E., and Kraut, R. (2008). A fluorescent glycolipid-binding peptide probe traces cholesterol dependent microdomain-derived trafficking pathways. PLoS ONE 3, e2933. doi:10.1371/journal.pone.0002933

Stone, J. M., Heard, J. E., Asai, T. and Ausubel, F. M. (2000). Simulation of fungal-mediated cell death by fumonisin $\mathrm{B} 1$ and selection of fumonisin B1-resistant (fbr) Arabidopsis mutants. Plant Cell 12, 1811-1822.

Suharsono, U., Fujisawa, Y., Kawasaki, T., Iwasaki, Y., Satoh, H., and Shimamoto, K. (2002). The heterotrimeric $\mathrm{G}$ protein alpha subunit acts upstream of the small GTPase Rac in disease resistance of rice. Proc. Natl. Acad. Sci. U.S.A. 99, 13307-13312.

Sweat, T. A., Lorang, J. M., Bakker, E. G., and Wolpert, T. J. (2008). Characterization of natural and induced variation in the LOV1 gene, a CCNB-LRR gene conferring victorin sensitivity and disease susceptibility in Arabidopsis. Mol. Plant Microbe Interact. 21, 7-19.

Sydenham, E. W., Gelderblom, W. C. A., Thiel, P. G., and Marasas, W. F. O. (1990). Evidence for the natural occurrence of fumonisin-B1, a mycotoxin produced by Fusarium moniliforme, in corn. J. Agric. Food Chem. 38, 285-290.

Tafesse, F. G., and Holthuis, J. C. (2010). Cell biology: a brake on lipid synthesis. Nature 463, 1028-1029.

Takahashi, Y., Berberich, T., Kanzaki, H., Matsumura, H., Saitoh, H., Kusano, T., and Terauchi, R. (2009). Serine palmitoyltransferase, the first step enzyme in sphingolipid biosynthesis, is involved in nonhost resistance. Mol. Plant Microbe Interact. 22, 31-38.

Tanaka, T., Abbas, H. K., and Duke, S. O. (1993). Structure-dependent phytotoxicity of fumonisins and relatedcompounds in a duckweed bioassay. Phytochemistry 33, 779-785.

Teng, C., Dong, H., Shi, L., Deng, Y., Mu, J., Zhang, J., Yang, X., and Zuo, J. (2008). Serine palmitoyltransferase, a key enzyme for de novo synthesis of sphingolipids, is essential for male gametophyte development in Arabidopsis. Plant Physiol. 146, 1322-1332.

Ternes, P., Feussner, K., Werner, S., Lerche, J., Iven, T., Heilmann, I. Riezman, H., and Feussner, I. (2011). Disruption of the ceramide synthase LOH1 causes spontaneous cell death in Arabidopsis thaliana. New Phytol. 192, 841-854.

Thiel, P. G., Marasas, W. F. O., Sydenham, E. W., Shephard, G. S., Gelderblom, W. C. A., and Nieuwenhuis, J. J. (1991). Survey of fumonisin production by Fusarium species. Appl. Environ. Microbiol. 57, 1089-1093.

Thomma, B. P., Nurnberger, T., and Joosten, M. H. (2011). Of PAMPs and effectors: the blurred PTI-ETI dichotomy. Plant Cell 23, 4-15.

Townley, H. E., Mcdonald, K., Jenkins, G. I., Knight, M. R., and Leaver, C. J. (2005). Ceramides induce programmed cell death in Arabidopsis cells in a calciumdependent manner. Biol. Chem. 386, 161-166.

Tsegaye, Y., Richardson, C. G., Bravo, J. E., Mulcahy, B. J., Lynch, D. V., Markham, J. E., Jaworski, J. G., Chen, M., Cahoon, E. B., and Dunn, T. M. (2007). Arabidopsis mutants lacking long chain base phosphate lyase are fumonisin-sensitive and accumulate trihydroxy-18:1 long chain base phosphate. J. Biol. Chem. 282, 28195-28206.

Umemura, K., Ogawa, N., Yamauchi, T., Iwata, M., Shimura, M., and Koga, J. (2000). Cerebroside elicitors found in diverse phytopathogens activate defense responses in rice plants. Plant Cell Physiol. 41, 676-683. 
Umemura, K., Tanino, S., Nagatsuka, T., Koga, J., Iwata, M., Nagashima, K., and Amemiya, Y. (2004). Cerebroside elicitor confers resistance to Fusarium disease in various plant species. Phytopathology 94, 813-818.

Vailleau, F., Daniel, X., Tronchet, M., Montillet, J. L., Triantaphylides, C., and Roby, D. (2002). A R2R3-MYB gene, AtMYB30, acts as a positive regulator of the hypersensitive cell death program in plants in response to pathogen attack. Proc. Natl. Acad. Sci. U.S.A. 99, 10179-10184.

van Der Meer-Janssen, Y. P., Van Galen, J., Batenburg, J. J., and Helms, J. B. (2010). Lipids in host-pathogen interactions: pathogens exploit the complexity of the host cell lipidome. Prog. Lipid Res. 49, 1-26.

van Doorn, W. G. (2011). Classes of programmed cell death in plants, compared to those in animals. J. Exp. Bot. 62, 4749-4761.

van Doorn, W. G., Beers, E. P., Dangl, J. L., Franklin-Tong, V. E., Gallois, P., Hara-Nishimura, I., Jones, A. M., Kawai-Yamada, M., Lam, E., Mundy, J., Mur, L. A., Petersen, M., Smertenko, A., Taliansky, M., Van Breusegem, F., Wolpert, T., Woltering, E., Zhivotovsky, B., and Bozhkov, P. V. (2011). Morphological classification of plant cell deaths. Cell Death Differ. 18, 1241-1246.

van Zanten, T. S., Cambi, A., Koopman, M., Joosten, B., Figdor, C. G., and Garcia-Parajo, M. F. (2009). Hotspots of GPI-anchored proteins and integrin nanoclusters function as nucleation sites for cell adhesion. Proc. Natl. Acad. Sci. U.S.A. 106, 18557-18562.

van Zanten, T. S., Gomez, J., Manzo, C., Cambi, A., Buceta, J., Reigada, R., and Garcia-Parajo, M. F. (2010). Direct mapping of nanoscale compositional connectivity on intact cell membranes. Proc. Natl. Acad. Sci. U.S.A. 107, 15437-15442.

Verheij, M., Bose, R., Lin, X. H., Yao, B., Jarvis, W. D., Grant, S., Birrer, M. J., Szabo, E., Zon, L. I., Kyriakis, J. M., Haimovitz-Friedman, A., Fuks, Z., and Kolesnick, R. N. (1996). Requirement for ceramideinitiated SAPK/JNK signalling in stress-induced apoptosis. Nature 380, 75-79.

Vieira, F. S., Correa, G., Einicker-Lamas, M., and Coutinho-Silva, R. (2010). Host-cell lipid rafts: a safe door for micro-organisms? Biol. Cell 102, 391-407.

Wang, D., Griffitts, J., Starker, C., Fedorova, E., Limpens, E., Ivanov, S., Bisseling, T., and Long, S. (2010). A nodule-specific protein secretory pathway required for nitrogen-fixing symbiosis. Science 327, 1126-1129.

Wang, D., Weaver, N. D., Kesarwani, M., and Dong, X. (2005). Induction of protein secretory pathway is required for systemic acquired resistance. Science 308, 1036-1040.

Wang, H., Jones, C., Ciaccizanella, J., Holt, T., Gilchrist, D. G., and Dickman, M. B. (1996a). Fumonisins and Alternaria alternata lycopersici toxins: sphinganine analog mycotoxins induce apoptosis in monkey kidney cells. Proc. Natl. Acad. Sci. U.S.A. 93, 3461-3465

Wang, H., Li, J., Bostock, R. M., and Gilchrist, D. G. (1996b). Apoptosis: a functional paradigm for programmed plant cell death induced by a host-selective phytotoxin and invoked during development. Plant Cell 8, 375-391.

Wang, J. W., Zheng, L. P., and Tan, R. X. (2007). Involvement of nitric oxide in cerebroside-induced defense responses and taxol production in Taxus yunnanensis suspension cells. Appl. Microbiol. Biotechnol. 75, 1183-1190.

Wang, W., Wen, Y., Berkey, R., and Xiao, S. (2009). Specific targeting of the Arabidopsis resistance protein RPW8.2 to the interfacial membrane encasing the fungal haustorium renders broad-spectrum resistance to powdery mildew. Plant Cell 21, 2898-2913.

Wang, W., Yang, X., Tangchaiburana, S., Ndeh, R., Markham, J. E., Tsegaye, Y., Dunn, T. M., Wang, G. L., Bellizzi, M., Parsons, J. F., Morrissey, D., Bravo, J. E., Lynch, D. V., and Xiao, S. (2008). An inositolphosphorylceramide synthase is involved in regulation of plant programmed cell death associated with defense in Arabidopsis. Plant Cell 20, 3163-3179.

Watanabe, N., and Lam, E. (2006). Arabidopsis Bax inhibitor-1 functions as an attenuator of biotic and abiotic types of cell death. Plant J. 45, 884-894.

Watanabe, N., and Lam, E. (2008). Arabidopsis Bax inhibitor-1: a rheostat for ER stress-induced programmed cell death. Plant Signal Behav 3, 564-566.

Wattenberg, E. V., Badria, F. A., and Shier, W. T. (1996). Activation of mitogen-activated protein kinase by the carcinogenic mycotoxin fumonisin B1. Biochem. Biophys. Res. Commun. 227, 622-627.

Wiermer, M., Feys, B. J., and Parker, J. E. (2005). Plant immunity: the EDS1 regulatory node. Curr. Opin. Plant Biol. 8, 383-389.

Williams, L. D., Glenn, A. E., Zimeri, A. M., Bacon, C. W., Smith, M. A., and
Riley, R. T. (2007). Fumonisin disruption of ceramide biosynthesis in maize roots and the effects on plant development and Fusarium verticillioides-induced seedling disease. $J$. Agric. Food Chem. 55, 2937-2946.

Wispriyono, B., Schmelz, E., Pelayo, H., Hanada, K., and Separovic, D. (2002). A role for the de novo sphingolipids in apoptosis of photosensitized cells. Exp. Cell Res. 279 , 153-165.

Witsenboer, H. M. A., Kloosterziel, K. M., Hateboer, G., Nijkamp, H. J. J., and Hille, J. (1992). Tomato susceptibility to Alternaria stem canker parameters involved in host-specific toxin-induced leaf necrosis. Plant Sci. 81, 127-134.

Worrall, D., Liang, Y. K., Alvarez, S., Holroyd, G. H., Spiegel, S., Panagopulos, M., Gray, J. E., and Hetherington, A. M. (2008). Involvement of sphingosine kinase in plant cell signalling. Plant J. 56, 64-72.

Xia, Y., Gao, Q. M., Yu, K., Lapchyk, L., Navarre, D., Hildebrand, D., Kachroo, A., and Kachroo, P. (2009). An intact cuticle in distal tissues is essential for the induction of systemic acquired resistance in plants. Cell Host Microbe 5, 151-165.

Xia, Y., Yu, K., Navarre, D., Seebold, K., Kachroo, A., and Kachroo, P. (2010). The glabral mutation affects cuticle formation and plant responses to microbes. Plant Physiol. 154 833-846.

Xiao, S., Calis, O., Patrick, E., Zhang, G., Charoenwattana, P., Muskett, P., Parker, J. E., and Turner, J. G. (2005). The atypical resistance gene, RPW8, recruits components of basal defence for powdery mildew resistance in Arabidopsis. Plant J. 42, 95-110.

Xiao, S., Ellwood, S., Calis, O., Patrick, E., Li, T., Coleman, M., and Turner, J. G. (2001). Broad-spectrum mildew resistance in Arabidopsis thaliana mediated by RPW8. Science 291, 118-120.

Xiong, T. C., Coursol, S., Grat, S., Ranjeva, R., and Mazars, C. (2008). Sphingolipid metabolites selectively elicit increases in nuclear calcium concentration in cell suspension cultures and in isolated nuclei of tobacco. Cell Calcium 43, 29-37.

Yasuda, M., Ishikawa, A., Jikumaru, Y., Seki, M., Umezawa, T., Asami, T., Maruyama-Nakashita, A., Kudo, T., Shinozaki, K., Yoshida, S., and Nakashita, H. (2008). Antagonistic interaction between systemic acquired resistance and the abscisic acid-mediated abiotic stress response in Arabidopsis. Plant Cell 20, 1678-1692.
Yoshizaki, F., Nakayama, H., Iwahara, C., Takamori, K., Ogawa, H., and Iwabuchi, K. (2008). Role of glycosphingolipid-enriched microdomains in innate immunity: microdomain-dependent phagocytic cell functions. Biochim. Biophys. Acta 1780, 383-392.

Yu, X., Wang, X., Huang, X., Buchenauer, H., Han, Q., Guo, J., Zhao, J., Qu, Z., Huang, L., and Kang, Z. (2011). Cloning and characterization of a wheat neutral ceramidase gene Ta-CDase. Mol. Biol. Rep. 38, 3447-3454.

Zauner, S., Ternes, P., and Warnecke, D. (2010). "Biosynthesis of sphingolipids in plants (and some of their functions)," in Sphingolipids as Signaling and Regulatory Molecules, eds C. Chalfant and M. Delpoeta (Berlin: Springer-Verlag), 249-263.

Zhang, J., Shao, F., Li, Y., Cui, H., Chen, L., Li, H., Zou, Y., Long, C., Lan, L., Chai, J., Chen, S., Tang, X., and Zhou, J. M. (2007). A Pseudomonas syringae effector inactivates MAPKs to suppress PAMP-induced immunity in plants. Cell Host Microbe 1, 175-185.

Zhang, S., Liu, Y., and Klessig, D. F. (2000). Multiple levels of tobacco WIPK activation during the induction of cell death by fungal elicitins. Plant J. 23, 339-347.

Zheng, H., Rowland, O., and Kunst, L. (2005). Disruptions of the Arabidopsis Enoyl-CoA reductase gene reveal an essential role for very-long-chain fatty acid synthesis in cell expansion during plant morphogenesis. Plant Cell 17, 1467-1481.

Conflict of Interest Statement: The authors declare that the research was conducted in the absence of any commercial or financial relationships that could be construed as a potential conflict of interest.

Received: 03 January 2012; accepted: 22 March 2012; published online: 10 April 2012.

Citation: Berkey $R$, Bendigeri $D$ and Xiao S (2012) Sphingolipids and plant defense/disease: the "death" connection and beyond. Front. Plant Sci. 3:68. doi: 10.3389/fpls.2012.00068

This article was submitted to Frontiers in Plant Physiology, a specialty of Frontiers in Plant Science.

Copyright (C) 2012 Berkey, Bendigeri and Xiao. This is an open-access article distributed under the terms of the Creative Commons Attribution Non Commercial License, which permits noncommercial use, distribution, and reproduction in other forums, provided the original authors and source are credited. 